\title{
Autonomía Local, equilibrio presupuestario y sostenibilidad financiera. Tendencias y perspectivas contemporáneas en las relaciones de tutela financiera y control presupuestario local en España (2008-2014)
}

\author{
Bernabé Aldeguer CERdÁ \\ Universidad de Alicante \\ bernabealdeguer@gmail.com
}

Recibido: 23/10/2014

Aceptado: 27/11/2014

\begin{abstract}
Resumen
El presente artículo tiene como principal propósito analizar las relaciones multinivel de coordinación interadministrativa entre el Estado y las EELL en materia de control presupuestario y tutela financiera. Se pretende evaluar el impacto de las recientes reformas sobre equilibrio presupuestario y sostenibilidad financiera sobre el margen y el alcance de la Autonomía Local, a la luz de la normativa comunitaria europea y la reforma del artículo 135 de la Constitución Española. Los resultados se agrupan en el estudio del régimen de autorización de las operaciones de crédito, el control y el cumplimiento forzoso de las medidas de sostenibilidad financiera y estabilidad presupuestaria de las EELL, la necesidad de informar a los organismos del Estado (Ministerio de Hacienda), y las responsabilidades de los funcionarios de Administración Local con habilitación estatal en el control de la gestión presupuestaria y la consecución de la sostenibilidad financiera de las EELL. Finalmente, se destaca también el componente tecnocrático o economicista que ha presidido la legitimación de las reformas adoptadas en el régimen local, sugiriendo la necesidad de vigorizar el componente democrático y participativo de las EELL en la gestión presupuestaria, como parte del fortalecimiento de la Autonomía Local y frente a los crecientes controles financieros.
\end{abstract}

Palabras clave: Autonomía Local, Déficit público, deuda pública, Entidades Locales (EELL), equilibrio presupuestario, sostenibilidad financiera, tutela financiera.

Local Autonomy, budget balance and financial sustainability. Contemporary trends and perspectives on the local financial supervision and budget control in Spain (2008-2014)

\begin{abstract}
The purpose of the article is to analyze the multilevel relationships of inter-administrative coordination between state and local entities (LES) in terms of budget control and financial supervision. It aims to assess the impact of the most recent reforms on budgetary balance and financial sustainability on the scope and reach of Local Autonomy in the light of European Union law and the reform of article 135 of the Spanish Constitution. The results are grouped in the study of arrangements for approving credit operations, the control and enforcement of the measures of financial sustainability and fiscal stability of the LES, the duty to inform state agencies (Ministry of Finance), and the responsibilities of Local Government officials with state enabling control of budget management and the achievement of financial sustainability of the
\end{abstract}


LES. Finally, the research exposes the technocratic or economistic component that has presided over the legitimacy of the reforms adopted in the local regime stands, suggesting the need to reinvigorate the democratic and participatory component of the LES in budget management, as part of strengthening the Local Autonomy and facing the growing financial controls.

Key words: Local Autonomy, public deficit, public debt, Local Entities, balanced budget, financial sustainability, financial supervision.

\section{Introducción}

A lo largo de los últimos años y de manera crecientemente acelerada, las Entidades Locales (en adelante, EELL) han experimentado una significativa y profunda transformación de su régimen jurídico a nivel presupuestario y financiero. Tales cambios han acontecido en el marco de las reformas adoptadas fundamentalmente a partir del año 2008 en lo relativo a las medidas contra la la falta de recursos financieros municipales, el control del déficit y de los límites de la deuda pública ${ }^{1}$, así como la consecución de la sostenibilidad financiera, económica y presupuestaria.

En este escenario, resulta insoslayable y ciertamente pertinente realizar una evaluación acerca del impacto que se ha derivado de las vigentes políticas de control del déficit y de la deuda pública sobre el régimen de las EELL, en términos de su incidencia sobre la Autonomía Local. Las limitaciones y los mecanismos de supervisión -tanto formales como materiales- que se han venido reforzando paulatinamente en orden a la consolidación de un mayor control de las cuentas públicas locales por parte de los organismos estatales particularmente -y de los autonómicos, en menor medida-, trascienden al alcance y al propio contenido de un conjunto de principios, instrumentos y conceptos esenciales entre los que destacan los de Autonomía Local o Suficiencia Financiera. Si bien, resultaría inapropiado obviar los efectos resultantes de tales reformas sobre la propia articulación representativa y eminentemente política y democrática de las Corporaciones Locales -democráticamente electas y constituidas-, así como sobre su margen de decisión en virtud de los recursos disponibles y de los controles a los que se ven sujetas.

A la tradicional dependencia financiera de las EELL como consecuencia de su sujeción a las transferencias finalistas o por participación presupuestaria procedentes del Estado y de las Comunidades Autónomas (en adelante, CCAA), cabe añadir la paulatina consolidación de un extenso y exhaustivo catálogo normativo dirigido a incrementar no sólo la cantidad, sino también la cualitativa capacidad de control ejercida

${ }^{1}$ En base a lo establecido en el Reglamento (CE) núm. 479/2009 del Consejo, de 25 de mayo de 2009, sobre la implementación del Protocolo sobre el procedimiento aplicable en caso de déficit excesivo, y al amparo de lo dispuesto en el Tratado Constitutivo de la Comunidad Europea, las recientes normas sobre endeudamiento - v. gr., Planes de Pagos a Proveedores-, computan como deuda los créditos financieros, los valores de renta fija, los préstamos o créditos transferidos a terceros, factoring sin recurso, Fondo de Financiación Pago a Proveedores; y, Asociaciones Públicas Privadas (APP's). 
por las instituciones y los organismos estatales sobre las EELL. De forma particular, tales controles destacan por cuanto se refiere de forma específica a los mecanismos de disciplina presupuestaria y de control del déficit, así como la sostenibilidad financiera y el régimen de endeudamiento. Todo ello ha venido a incidir de manera substancial sobre el margen de autonomía fiscal y financiera de las EELL.

En este sentido, los subsiguientes párrafos que hilvanan el presente artículo se enmarcan en una de las líneas de interés para la Ciencia de la Administración; a saber: el estudio de las relaciones interadministrativas entre diferentes Administraciones Públicas (en adelante, AAPP) u organismos de distinto nivel, en este caso del Estado y de las EELL, en el ámbito específico de las políticas y del ordenamiento jurídico sobre el control del déficit y de la deuda pública. Desde una perspectiva institucionalista, se aborda el análisis de los cambios en la regulación de los procedimientos previstos en el ejercicio de la tutela financiera, así como el régimen de autorización para la concertación de operaciones de crédito por parte de las EELL.

De acuerdo con lo expuesto, el objetivo del trabajo consiste en estudiar las relaciones interadministrativas de colaboración, coordinación y control que con carácter multinivel son ejercidas por las instituciones y los organismos estatales sobre las EELL. La investigación tiene el propósito de evaluar modestamente los efectos que sobre la Autonomía Local y financiera de las EELL han tenido las recientes medidas relacionadas con la reforma del régimen local. Así pues, se considera el impacto de tales cambios normativos sobre los mecanismos de control y de autorización establecidos para la concertación de operaciones de crédito y la ejecución de los correspondientes planes de reequilibrio, ajuste o saneamiento financiero, como parte de las políticas adoptadas en la consecución de los objetivos de déficit y deuda pública. Por ello, se estudian las relaciones entre el nivel local de Gobierno y Administración de un lado, y las instituciones y los organismos encargados de la tutela en materia de control financiero de otra parte, teniendo en cuenta el eventual impacto de tales relaciones sobre el alcance de la Autonomía Local. El trabajo se enmarca en el período cronológico comprendido entre el año 2008, en que se aprobó la primera medida con un significativo impacto e interés a efectos del objetivo de investigación (Real Decreto-Ley 9/2008, de 28 de noviembre, por el que se crea un Fondo Estatal de Inversión Local y un Fondo Especial del Estado para la Dinamización de la Economía y el Empleo), y el momento actual de la investigación (año 2014), etapa diacrónica en la que operan las reformas legislativas relacionadas con el objetivo y la hipótesis de trabajo.

La hipótesis de trabajo sostiene que las recientes medidas de tutela financiera (adoptadas como transposición de la normativa europea en materia de estabilidad presupuestaria y sostenibilidad financiera a través del ordenamiento jurídico español, y que han sido implementadas fundamentalmente por el Gobierno del Estado a través del Ministerio de Hacienda y de AAPP), han tenido un impacto significativo sobre el alcance y la extensión del principio de Autonomía Local, como consecuencia de los mayores controles y de los mecanismos de tutela en la gestión presupuestaria y financiera local, comprometiendo y limitando de este modo el margen de actuación autónoma e independiente de las EELL.

El artículo se estructura en cuatro partes claramente diferenciadas. Una primera parte dedicada a la exposición sucinta de los términos y el alcance de la Autonomía 
Local y la importancia del componente económico o hacendístico en la configuración de aquella. Se destaca el equilibrio de la Autonomía Local en confluencia con la necesaria coordinación interadministrativa con respecto al resto de las AAPP y niveles de Gobierno. A continuación se exponen los efectos y el impacto que se han derivado de las recientes reformas locales relativas al régimen presupuestario desde una aproximación a las relaciones interadministrativas entre las EELL y los organismos del Estado encargados de ejercer la tutela financiera. Para ello, se procede al estudio del régimen de autorización de las operaciones de crédito; el control y el cumplimiento forzoso de las medidas de sostenibilidad financiera y estabilidad presupuestaria de las EELL; la necesidad de informar a los organismos del Estado (Ministerio de Hacienda y Administraciones Públicas); y, las responsabilidades de los funcionarios de Administración Local con habilitación estatal en el control de la gestión presupuestaria y la consecución de la sostenibilidad financiera de las EELL. Finalmente, este estudio culmina con un apartado de consideraciones finales y de reflexiones acerca de los resultados expuestos, especificando posibles alternativas doctrinales y prácticas de futuro.

\section{La autonomía y la suficiencia financiera de las EELL en el marco de las relaciones multinivel}

El reconocimiento formal la Autonomía Local ${ }^{2}$ por medio de la Constitución Española (en adelante, CE) implica la articulación de un conjunto de atribuciones, competencias y facultades entre las que cabe considerar «un cierto grado de capacidad normativa y de suficiencia financiera (artículos 140, 141, 142)» (Ruano, 2002). De acuerdo con Canales Aliende \& Pérez: «el principio de autonomía, a su vez, hace referencia a la capacidad de gestión de una parte de los asuntos públicos por parte de una Administración Territorial, con respecto de su núcleo competencial por parte de otras Administraciones de niveles territoriales diferentes» (Canales Aliende \& Pérez, 2002). La Autonomía Local tiene igualmente reconocida su garantía en el ámbito comunitario europeo por mor del artículo 4.2 del Tratado de la Unión Europea (TUE), en virtud del cual: «la Unión respetará la igualdad de los Estados miembros ante los Tratados, así como su identidad nacional, inherente a las estructuras fundamentales políticas y constitucionales de éstos, también en lo referente a la autonomía local y regional» (TUE, 1992).

En el bloque de constitucionalidad referente a la Autonomía Local y la Suficiencia Financiera, dado por el compendio de los anteriormente citados artículos 140 a 142,

${ }^{2}$ La relevancia de la Autonomía Local como fundamento para la consecución del bienestar social y la garantía de las comunidades locales en la gestión de sus propios recursos e intereses hunde sus raíces en la más solariega doctrina política y administrativa, sirviendo de ejemplo el modo en que Colmeiro comparecería al respecto, señalando que la autonomía: «debe a lo menos respetarse en cuanto lo permita la concordancia de los intereses generales y municipales» (Colmeiro, 1870). Retrotrayendo la atención a pocas décadas previas a las de la cita precedente, el propio Alexis de Tocqueville anotaría y advertiría sobre la crucial importancia del municipio en tanto que origen para el ejercicio de la libertad de las sociedades, de suerte que: «las instituciones municipales son a la libertad lo que las escuelas primarias a la ciencia» (Tocqueville, 1980). 
destaca la garantía de la autonomía de los municipios por parte de la CE (art. 140)ª , así como el establecimiento de los fundamentos de la Suficiencia Financiera por medio del artículo 142, según el cual: «las Haciendas locales deberán disponer de los medios suficientes para el desempeño de las funciones que la ley atribuye a las Corporaciones respectivas y se nutrirán fundamentalmente de tributos propios y de participación en los del Estado y de las Comunidades Autónomas» (art. $142 \mathrm{CE}$ ). Tal autonomía se proyecta en el ámbito de la hacienda pública local, tanto en la dimensión de los gastos como en la de los ingresos.

La Autonomía Local permite a las EELL disponer de sus propias haciendas en cuanto a la gestión de las mismas en ambas facetas de los ingresos y de los gastos, de tal suerte que la Suficiencia Financiera convierte la Autonomía en: «una realidad material, generando recursos económicos de un volumen adecuado» (Alonso Higuera, 2002). De acuerdo con De Vicente: «la autonomía financiera municipal aparece como una especie dentro de aquél género, y es la que posibilita que aquella pueda hacerse efectiva» (De Vicente, 2002), deviniendo la «autonomía financiera de las Haciendas Locales como consecuencia lógica de la autonomía institucional» (Navarro Fauré, 2012). Así pues, a la luz de la propia Exposición de Motivos de la Ley 39/1988, de 28 de diciembre, reguladora de las Haciendas Locales: «la suficiencia financiera enmarca las posibilidades reales de la autonomía local, pues, sin medios económicos suficientes, el principio de autonomía no pasa de ser una mera declaración formal» (Ley 39/1988, de 28 de diciembre).

De forma específica, la capacidad para la obtención de los medios financieros suficientes -incluyendo las operaciones de crédito o de endeudamiento- con que sostener y garantizar la viabilidad de la Gestión Pública en el ejercicio de las competencias atribuidas a las EELL, constituye un componente inherente a la propia Autonomía Local, en tanto en cuanto tal disposición de medios y recursos permite «la consecución efectiva de la autonomía constitucionalmente garantizada» (STC 96/1990, de 24 de mayo, F. J. $7^{\circ}$ ). Así, como proyección de la autonomía en el ámbito crediticio, la propia Carta Europea de la Autonomía Local (Consejo de Europa, 1985) reconoce en su artículo 9.8 que: «con el fin de financiar sus gastos de inversión, las Entidades Locales deben tener acceso de conformidad con la Ley, al mercado nacional de capitales» (Carta Europea de la Autonomía Local, 1985).

A pesar del reconocimiento constitucional de la Autonomía Local, dicho principio queda sujeto a un conjunto de límites que se materializan por medio de diversos y múltiples controles ejercidos con carácter multinivel por parte de las instituciones y los

3 Artículo 140 CE: «La Constitución garantiza la autonomía de los municipios. Estos gozarán de personalidad jurídica plena. Su gobierno y administración corresponde a sus respectivos Ayuntamientos, integrados por los Alcaldes y los Concejales. Los Concejales serán elegidos por los vecinos del municipio mediante sufragio universal, igual, libre, directo y secreto, en la forma establecida por la ley. Los Alcaldes serán elegidos por los Concejales o por los vecinos. La ley regulará las condiciones en las que proceda el régimen del concejo abierto». 
organismos del Estado y de las CCAA. Tales controles encuentran su legitimación o justificación originaria en la propia normativa básica al amparo del artículo $103.1 \mathrm{CE}^{4}$ y del ámbito regulatorio de las Administraciones Públicas, de acuerdo con el cual se viene a reconocer en favor del Estado y con carácter exclusivo la regulación de «las bases del régimen jurídico de las AAPP $\rangle^{5}$ (artículo 149.1.18 $\mathrm{CE}$ ). Igualmente, se incluye en dicha potestad regulatoria la relativa a las bases del régimen jurídico de las EELL y el de las Haciendas de la mismas, a lo cual cabe adicionar el ejercicio de las competencias de ejecución, en las que se enmarca la tutela financiera. Las relaciones interadministrativas permiten dotar así de coherencia al conjunto de las AAPP, en la consecución del interés general (Sánchez Sáez, 2008). Si bien, no es posible obtener del texto constitucional ninguna disposición concreta relativa a las relaciones multinivel entre el Estado y las EELL ante el silencio que al respecto guarda la CE (Crespo, $2002)^{6}$. Se debe advertir igualmente la existencia de límites a la Autonomía Local como consecuencia de las «relaciones políticas y administrativas -intergubernamentales, en su vocablo anglosajón- entre instituciones pertenecientes a niveles territoriales distintos» (Ruano, 2002).

El ámbito del Gobierno y de la Administración Local se incardina por consiguiente en complejas relaciones institucionalizadas con el resto de las instituciones y $\mathrm{AAPP}^{7}$. De acuerdo con Ruano: «(...) las relaciones entre autoridades locales y centrales se caracterizan por la complejidad de sus vínculos de asociación y su interdependencia mutua, que se materializa en relaciones de cooperación y conflicto» (Ruano, 2002), y que igualmente se proyectan sobre la faceta económico-financiera de la Autonomía Local. Frente al innegable «proceso de transferencias hacia abajo, hacia unidades subestatales» (Ribó \& Pastor, 1999) como resultado de una política de moderniza-

${ }^{4}$ Artículo 103.1 CE: «La Administración Pública sirve con objetividad los intereses generales y actúa de acuerdo con los principios de eficacia, jerarquía, descentralización, desconcentración y coordinación, con sometimiento pleno a la ley y al Derecho» (art. 103.1 CE).

${ }^{5}$ De acuerdo con Queralt cabe señalar que al igual que se establece en relación a la legislación básica de régimen local, también se fija: «(...) por los entes superiores el régimen jurídico del Presupuesto Local. Esto es, la normativa presupuestaria a la que habrán de ajustarse las Corporaciones Locales al aprobar y ejecutar su Presupuesto» (Queralt et alt., 2011).

6 La Sentencia del Tribunal Supremo, de 23 de Octubre de 1999, declaró que: «de todos es sabido que, como ha señalado la doctrina, la regulación constitucional de las EELL no levantó especial interés entre los constituyentes, que no le dieron gran desarrollo, más atraídos por la innovación que representaban las CCAA» (STS, 23 de Octubre de 1999).

${ }^{7}$ La compleja realidad de las relaciones interadministrativas entabladas por parte de las EELL con otros niveles administrativos abarca las relaciones entre los municipios y las provincias, las diferentes fórmulas de cooperación supramunicipal (v. gr., las mancomunidades), la coordinación interinstitucional con el conjunto de las AAPP autonómicas y del Estado en la prestación de diversos servicios públicos, los programas de cooperación económica local, la incardinación de las EELL en el seno de la Federación Española de Municipios y Provincias (FEMP) y sus delegaciones autonómicas federadas, la coordinación tributaria entre diferentes AAPP, o la propia participación en entidades supranacionales, tales como el Comité de las Regiones (CDR) de la Unión Europea (UE). Del mismo modo, cabe tener en consideración la creciente y cada vez más habitual colaboración horizontal (formal e informal) entre los actores institucionales y políticos de un determinado nivel de Gobierno y Administración (Colino, 2011). 
ción definida por «procesos descentralizadores mediante la transferencia de poderes o competencias a distintos niveles de Gobierno y Administración» (Olías de Lima, 2002), y que en el caso español ha caracterizado el iter de la construcción y la consolidación autonómica ${ }^{8}$, el ámbito local ha estado sujeto a transformaciones que han relativizado y limitado su ámbito y capacidad de acción y gestión autónoma a nivel económico-financiero y presupuestario.

En el marco del modelo municipal español, la actividad de las EELL ha estado sujeta a históricas relaciones de dependencia jerárquica, así como a tutelas por parte de la Administración del Estado9 (Quintana, 2008). La tutela financiera de los organismos del Estado o de las CCAA que tengan atribuida tal competencia sobre las entidades, los organismos, los entes y las sociedades incardinadas en el sector público local (Bachiller, 2005), abarca el conjunto de los actos administrativos de ejecución en el ámbito financiero, de acuerdo con el alcance del más amplio concepto de tutela. Así, como tal tutela cabe entender: «la técnica de intervención administrativa, en virtud de la cual, la entidad tutelante somete a una cierta disciplina unitaria a otras entidades administrativas, de rango inferior pero no jerárquicamente dependientes de aquélla, ejerciendo, en los términos legalmente previstos, determinadas potestades administrativas sobre la organización, sobre los actos o sobre la actividad de la entidad tutelada (controles de legalidad o de oportunidad, que se actúan a través de autorizaciones, aprobaciones, suspensiones, resoluciones de recursos, etcétera.; puede entenderse incluso a nombramientos y remociones de cargos») (Endemaño, 2014). De acuerdo con Villar Rojas:

${ }^{8}$ A modo indicativo, cabe tener en consideración la incidencia que ha tenido el desarrollo y la configuración del proceso autonómico en cuanto al régimen local con carácter general, y lo relativo al ejercicio de la tutela financiera en particular. En este sentido, la asunción de la competencia sobre la tutela financiera no ha quedado exenta de controversia, tal y como así lo testimonia la reciente Sentencia del Tribunal Constitucional 120/2012, de 5 de junio, dada la consolidación y la preeminencia que el Ministerio de Hacienda y Administraciones Públicas tiene reconocida para sí en este ámbito por medio del ordenamiento jurídico general. En el llamado proceso «de interiorización del régimen local de los Estatutos de Autonomía de segunda generación» (Álvarez García, 2013), ha primado la advertida limitación reconocida en el Fundamento Jurídico 36 de la Sentencia del Tribunal Constitucional 31/2010, de 28 de junio de 2010, acerca de «la competencia básica que al Estado le corresponde en la materia en virtud de la reserva del artículo 149.1.18 de la Constitución Española, por cuanto la expresión bases del régimen jurídico de las Administraciones Públicas engloba a las Administraciones Locales» (STC 31/2010, FJ 36).

${ }_{9}$ Siguiendo a Alonso Higuera, se da una: «distribución vertical del poder público entre entidades de diferente nivel, el nivel estatal, en cuanto titular de la soberanía, el autonómico, dotado de una autonomía política y el local, dotado de una autonomía administrativa» (Alonso Higuera, 2002). Igualmente, la Exposición de Motivos de la Ley 7/1985, de 2 de abril, Reguladora de las Bases del Régimen Local reconoce que: «por lo que hace a las relaciones interadministrativas, salta a la vista la radical inadecuación del mantenimiento en el nuevo y compuesto Estado constitucional de las técnicas y las categorías cristalizadas en el Estado centralista y autoritario. En particular, ese juicio de radical obsolescencia merece predicarse de las técnicas formalizadas actuables por voluntad unilateral de una de las administraciones e incidentes normalmente en la validez o la eficacia de los actos emanados de otra, en este sentido subordinada a la anterior, técnicas que no son sino trasunto y consecuencia lógicos de la construcción piramidal y jerárquica del poder público administrativo, puesto que la tutela, a la que todas ellas se reconducen, no es sino una categoría que expresa una situación de fuerte dependencia casi jerárquica» (Exposición de Motivos, Ley 7/1985, de 2 de abril, Reguladora de las Bases del Régimen Local). 
«en todo caso, más allá de su invalidez, lo cierto es que la tutela estatal con excusa financiera constituye ya un pilar básico de la ordenación y regulación de las entidades locales españolas» (Villar Rojas, 2014), pudiéndose bien considerar la tutela sobre las EELL como «algo más que una coordinación» (Cliset \& Grau, 1992). Más críticamente, Ezquiaga \& Muñoz consideraron la articulación contenida en la LBRL como un «trasnochado concepto de tutela del Estado» (Ezquiaga \& Muñoz (1996), valorando que la coordinación reviste en ocasiones una suerte de tutela, constituyendo ésta el envés de la Autonomía de las EELL (Tejerizo, 2003). En el marco del federalismo fiscal, en base al cual confluye la existencia de una «pluralidad de haciendas» (Navarro Fauré, 2013 $)^{10}$, las relaciones entre las distintas AAPP en materia financiera permite identificar el conjunto de las: «actividades o interacciones que se dan entre unidades de gobierno de todo tipo y nivel», tal y como Anderson define a partir del caso estadounidense (Chandler \& Plano, 1988). De forma específica, y en el contexto de dicha aproximación doctrinal, las Administraciones estatales -y en menor medida las regionaleshan venido ejerciendo de forma estructural, institucionalizada, reiterada y constante distintas competencias destinadas a limitar el acceso a las operaciones de crédito por parte de las EELL. Esta tendencia se ha formalizado a través de la autorización administrativa correspondiente por parte de los organismos del Estado en determinados supuestos. Si bien, en orden a su garantía ni la autonomía ni el autogobierno de las EELL: «(...) puede ser menoscabada por la interferencia de las autoridades del gobierno del Estado ni de su administración» (Vallès \& Brugué, 2001), lo cual no exonera a los municipios de quedar sujetos a numerosos mecanismos que limitan en la práctica el elenco de funciones, competencias y manifestaciones que materializan tal autonomía.

La continua doctrina constitucional y la jurisprudencia han venido a destacar la naturaleza administrativa de la Autonomía Local, lo cual ha legitimado y justificado que el Estado y las CCAA ejerzan: «la posibilidad de controlar a la actividad de las Corporaciones Locales, cuyos intereses son inferiores a los representados por el Legislador» (Sánchez Sáez, 2008). De forma coherente con lo expuesto, la libertad e independencia de actuación en que consiste la Autonomía Local: «(...) no es absoluta, no es total» (De Vicente García, 2002). Los límites que contempla el diseño institucional español han quedado elocuentemente legitimados por la doctrina constitucional al señalar que: «(...) dadas las diversas fuentes que nutren las Haciendas Locales, así como su complementariedad, es aquí plenamente aplicable la existencia de controles de legalidad, tanto en relación con la obtención de controles de legalidad, tanto en relación con la obtención y gestión de ingresos de carácter propio como en la utilización de los procedentes de otras fuentes (F. J. $5^{\circ}$, STC 4/1981, de 2 de Febrero).

No obstante lo señalado, y aun siendo eminentemente administrativa la naturaleza de la Autonomía Local, cabe no obviar en los términos del Fundamento Jurídico Tercero de la STC 32/1981, el componente político «que le viene atribuido a la Corporación Local por el origen democrático de sus componentes (lo cual) exige, como con-

${ }^{10}$ De acuerdo con Navarro Fauré: «los modelos constitucionales de organización territorial descentralizada, conllevan la existencia de diferentes niveles de la Hacienda Pública o diferentes Haciendas Públicas: una Hacienda Estatal, Autonómica y Local» (Navarro Fauré, 2013). 
tenido inherente, la capacidad de dirección político-administrativa de sus titulares en el ejercicio de las competencias propias de los entes locales» (Casado, 2008). Así pues, en la plural constelación de las Administraciones, los gobiernos y las instituciones públicas que se congregan en la constitución de un Estado compuesto como el español, y al albur del Fundamento Jurídico tercero de la Sentencia del Tribunal Constitucional, de 2 de febrero de 1981, el Estado queda situado en una posición de superioridad jerárquica sobre las EELL (FJ3 ${ }^{\circ}$, STC 2/2/1981). En este sentido, y a modo de ejemplo, cabría poner de manifiesto la evaluación que en el Libro Blanco para la reforma del Gobierno Local (2005) se vino a realizar sobre la imposición de los numerosos y diversos controles, tutelas y medidas de coordinación que al exigir distintas autorizaciones preceptivas, han operado en detrimento también de la autonomía local (Libro Blanco para la Reforma del Gobierno Local, 2005). No obstante, el propio documento citado destaca la necesidad de las relaciones interadministrativas -institucionalizadas y formalizadas - con objeto de materializar los principios de cooperación y coordinación, máxime en un Estado compuesto como el español (Libro Blanco para la Reforma del Gobierno Local, 2005).

Las EELL disponen de una proyección inexorable de la Autonomía Local en materia financiera, quedando sujeta sin embargo a diferentes principios y mecanismos de colaboración, cooperación y control interadministrativo. Específicamente para el caso español, la Ley 7/1985, de 2 de abril, Reguladora de las Bases del Régimen Local (en adelante, LRBRL) recoge el deber de «información mutua, colaboración, coordinación y respeto a los ámbitos competenciales respectivos» (art. 10.1 LRBRL), aludiendo a la especial coordinación de las competencias de las EELL, no sólo entre sí -en el mismo nivel de gobierno y Administración local con carácter horizontal-, sino fundamentalmente con respecto a «las de las restantes AAPP» (art. 10.2 LRBRL), sin que tal régimen de coordinación afecte en ningún caso a la autonomía de las EELL (art. 10.3 LRBRL) $)^{11}$. En este sentido, como parte de las recientes reformas de contenido económico-presupuestario, resulta relevante el papel del Gobierno del Estado para establecer los «mecanismos de coordinación entre todas las AAPP para garantizar la aplicación efectiva de los principios» de estabilidad presupuestaria y de sostenibilidad financiera, conforme a lo establecido en el art. 10.3 de la LO 2/2012, de 27 de abril, de Estabilidad Presupuestaria y Sostenibilidad Financiera (en adelante, LOEPSF). Así, corres-

11 Con carácter general, la Ley 7/1985, de 2 de abril, Reguladora de las Bases del Régimen Local, reconoce la posibilidad de que las leyes del Estado o de las CCAA puedan «crear, para la coordinación administrativa, órganos de colaboración de las Administraciones correspondientes con las Entidades locales. Estos órganos, que serán únicamente deliberantes o consultivos, podrán tener ámbito autonómico o provincial y carácter general o sectorial» (art. 58.1). Además, algunos acuerdos y organismos de colaboración entre el Estado y las EELL son el Consejo de Empadronamiento, Empadronamiento como órgano colegiado de colaboración entre la Administración General del Estado y los Entes Locales en materia padronal (art. 17.4); o, el Instituto de Estudios de Administración Local, que de acuerdo con el art. 96 de la Ley 7/1985, de 2 de abril, Reguladora de las Bases del Régimen Local: «desarrollará cursos de perfeccionamiento, especialización y promoción para los funcionarios al servicio de las Entidades locales, y colaborará en dichas funciones con los Institutos o Escuelas de funcionarios de las Comunidades Autónomas, así como con las instituciones de este tipo que acuerden constituir las propias Corporaciones». 
ponde al Gobierno observar la aplicación de tales principios «respetando en todo caso el principio de autonomía financiera de las Comunidades Autónomas y Corporaciones Locales» (art. 10.2 LOEPSF). En cualquier caso, las EELL deberán «valorar el impacto que sus actuaciones, en materia presupuestaria y financiera, pudieran provocar en el resto de AAPP» (art. 55.c LOEPSF). Finalmente, conviene señalar que las EELL, teniendo autonomía para el establecimiento y la exigencia de sus tributos en las fases de gestión, recaudación e inspección, lo harán en el marco: «de las fórmulas de colaboración con otras Entidades locales, con las Comunidades Autónomas o con el Estado, de acuerdo con lo que establezca la legislación del Estado» (art. 106.3 LRBRL).

En el sentido antedicho, la Ley 27/2013, de 27 de diciembre, de racionalización y sostenibilidad de la Administración Local (en adelante, LRSAL) incorporó un conjunto de preceptos acerca de las relaciones interadministrativas en las que quedan involucradas las EELL, a la luz de los principios de equilibrio presupuestario y sostenibilidad financiera. En base a lo expuesto por Villar Rojas: «la LRSAL se limita a seguir la senda ya trazada con ocasión de la crisis económico-financiera a través de las normas reguladoras de los mecanismos de endeudamiento municipal» (Villar Rojas, 2014). Respecto del impacto de tal normativa sobre la Autonomía Local cabe advertir que mientras que en la anterior redacción del artículo 10.3 LRBRL, la actividad del Gobierno del Estado derivaba en el hecho de que «las funciones de coordinación no afectaran en ningún caso a la autonomía de las entidades locales», la reciente reforma sustituye tal párrafo por la siguiente literalidad; a saber: «las funciones de coordinación serán compatibles con la autonomía de las entidades locales» (art. 10.4 LRBRL, tras la reforma de la LRSAL).

Las sucesivas disposiciones normativas del Estado y las más recientes del nivel autonómico -fruto fundamentalmente de las graduales reformas estatutarias realizadas, han venido estableciendo con diverso nivel de estabilidad y cambio un conjunto de organismos de coordinación intergubernamental o interadministrativo. De esta forma, en el organigrama de las relaciones interadministrativas entre el Estado y las EELL, cabe destacar la importancia de la Comisión Nacional de Administración Local y la Secretaría General de Coordinación Autonómica y Local. En el ámbito financiero, la Comisión Nacional de Administración Local ${ }^{12}$ tiene competencia para emitir informe, entre otros, en el supuesto del establecimiento de los «criterios para las autorizaciones de operaciones de endeudamiento de las Corporaciones locales» (art. 118.1.A.b), así como la realización de propuestas y sugerencias al Gobierno en materia de Administración local sobre las siguientes cuestiones: atribución y delegación de competencias

12 La Comisión Nacional de Administración Local, como órgano bilateral -Estado y EELL- regulado en el artículo 117 de la Ley 7/1985, de 2 de abril, Reguladora de las Bases del Régimen Local, y como parte del Título XI de la citada norma sobre las organizaciones para la cooperación de la Administración del Estado con la local, define a la misma como: «el órgano permanente para la colaboración entre la Administración General del Estado y la Administración local» (art. 117.1), formada: «bajo la presidencia del Ministro de Administraciones Públicas, por un número igual de representantes de las entidades locales y de la Administración General del Estado» (art. 117.2), correspondiendo la designación de los representantes de las entidades locales, «a la asociación de ámbito estatal con mayor implantación», esto es, a la Federación Española de Municipios y Provincias (FEMP). 
en favor de las EELL; distribución de las subvenciones, créditos y transferencias del Estado a la Administración local; participación de las Haciendas locales en los tributos del Estado; y, previsiones de los Presupuestos Generales del Estado que afecten a las EELL (art. 118.1.b). Así, y de forma concreta y específica, la Comisión Nacional de Administración Local: «se convierte (...) en un órgano de colaboración entre la Administración del Estado y las Entidades Locales respecto de las materias, objetivos y procedimientos de cumplimiento y determinación del principio de estabilidad presupuestaria (...)» (Queralt, 2011). Por su parte, a la Secretaría General de Coordinación Autonómica y Local ${ }^{13}$ le corresponde de manera concreta la dirección, el impulso y la coordinación de las competencias relativas a las relaciones con las entidades que integran la Administración Local ${ }^{14}$.

${ }^{13}$ Las funciones y la organización de la Secretaría General de Coordinación Autonómica y Local, se regulan en el artículo 13 del Real Decreto 256/2012, de 27 de enero, por el que se desarrolla la estructura orgánica básica del Ministerio de Hacienda y Administraciones Públicas. La redacción de dicho artículo fue reformada por medio del Real Decreto 696/2013, de 20 de septiembre, por el que se modifica el citado Real Decreto 256/2012, de 27 de enero.

${ }^{14}$ Las principales funciones ejercidas por dicho órgano directivo de la Administración Central, con respecto a las EELL, son las siguientes: la Secretaría del Consejo de Política Fiscal y Financiera de las Comunidades Autónomas y las relaciones con otros órganos de coordinación entre la Administración General del Estado, las comunidades autónomas y las corporaciones locales en el ámbito de competencias de la Secretaría General; el estudio, informe y propuesta de normas y medidas relativas al régimen tributario de los entes territoriales y a los regímenes tributarios especiales por razón del territorio, sin perjuicio de las competencias de la Dirección General de Tributos; la instrumentación y seguimiento de los mecanismos de financiación habilitados por la Administración General del Estado para las Comunidades Autónomas y las Entidades Locales, así como de los planes de ajuste acordados en este ámbito; la captación y el tratamiento de la información enviada por Comunidades Autónomas y Entidades locales, sobre sus entidades y organismos vinculados o dependientes, para la formación y mantenimiento de los inventarios de Entes del Sector Autonómico y Local, así como el análisis de esta información para la evaluación y elaboración de informes sobre el impacto del sector público autonómico y local en la actividad económico-financiera de las Administraciones Públicas, informando al Consejo de Política Fiscal y Financiera; la aplicación y gestión del sistema de financiación local; el estudio, informe y propuesta de las normas y medidas relativas a la financiación de las entidades locales, así como la secretaría de la Subcomisión de Régimen Económico, Financiero y Fiscal de la Comisión Nacional de Administración Local; la gestión de otros recursos estatales que financian a las entidades locales; la asistencia técnica y evacuación de consultas en relación con el régimen presupuestario y financiero de las entidades locales; el ejercicio de las facultades sobre autorizaciones legalmente atribuidas al Ministerio de Hacienda y Administraciones Públicas en relación con el endeudamiento de las entidades locales y el seguimiento del cumplimiento de los objetivos de estabilidad presupuestaria; y, la captación, tratamiento y difusión de los datos económico-financieros y tributarios de las entidades locales, así como el análisis y elaboración de informes, estadísticas y publicaciones relacionadas con aquella información. El ejercicio de las funciones enumeradas de carácter financiero, serán ejercidas por la Subdirección General de Estudios y Financiación de Entidades Locales, así como por la Subdirección General de Relaciones Financieras con las Entidades Locales. 


\section{Las relaciones interadministrativas de carácter multinivel entre las EELL y el Estado. Los efectos y el impacto de las reformas presupuestarias de control del déficit público}

Las políticas europeas de control presupuestario y sostenibilidad financiera de las Administraciones Públicas

El bagaje normativo europeo generado a lo largo de las últimas décadas y de manera fundamental a partir de la consolidación de la zona Euro o de la Unión Económica y Monetaria (en adelante, UEM), ha supuesto un aumento de los mecanismos de control dirigidos a garantizar las exigencias presupuestarias y el límite de deuda pública establecido a la luz del protocolo $\mathrm{n}^{\circ} .12$ sobre el procedimiento aplicable en caso de déficit excesivo, anexo al Tratado de la Unión Europea (TUE, 1992). De acuerdo con el citado tratado y en virtud de lo aprobado en el mismo sobre el control presupuestario, la normativa previa a la adopción del Pacto de Estabilidad y Crecimiento (1997), vino dada por el Reglamento (CE) no 1466 / 97 del Consejo, de 7 de julio de 1997, relativo al esfuerzo de la supervisión de las situaciones presupuestarias y a la supervisión y coordinación de las políticas económicas; el Reglamento (CE) nº 1467 / 97 del Consejo, de 7 de julio de 1997, relativo a la aceleración y clarificación del procedimiento de déficit excesivo; la Resolución del Consejo Europeo, de 17 de junio de 1997, relativa al Pacto de Estabilidad y Crecimiento; el Reglamento (CE) $\mathrm{n}^{\mathrm{o}} .1055$ / 2005, por el que se modifica el Reglamento (CE) n $n^{\circ}$. 1466 / 97 del Consejo, de 7 de julio de 1997, relativo al esfuerzo de la supervisión de las situaciones presupuestarias y a la supervisión y coordinación de las políticas económicas; y, el Reglamento (CE) no . 1056 / 2005, por el que se modifica el Reglamento (CE) no ${ }^{\circ} 1467$ / 97 del Consejo, de 7 de julio de 1997, relativo a la aceleración y clarificación del procedimiento de déficit excesivo. La última norma relevante vendrá dada por el Reglamento ${ }^{\circ} .1177$ / 2011 del Consejo, de 8 de noviembre de 2011, por el que se modifica el Reglamento (CE) $\mathrm{n}^{\mathrm{o}} .1467$ / 97 del Consejo, de 7 de julio de 1997, relativo a la aceleración y la clarificación del procedimiento de déficit excesivo, en el cual se articulan los mecanismos sobre control del déficit público del Tratado de Funcionamiento de la Unión Europea (en adelante, TFUE), y se sofistica la aplicación de sanciones en caso de su incumplimiento. En este sentido, la Directiva 2011/85/UE, del Consejo, de 8 de noviembre de 2011, sobre los requisitos aplicables a los marcos presupuestarios de los Estados miembros, plantea la normalización y la unificación de los sistemas de control presupuestario y de contabilidad pública en orden a mejorar de forma íntegra el control de las cuentas públicas nacionales de los Estados miembros por parte de las instituciones de la Unión Europea (en adelante, UE).

El Tratado de Estabilidad, Coordinación y Gobernanza de la UEM (en adelante, TECGUE) o Pacto Fiscal Europeo acordado el año 2012, parte de la prioridad y el supuesto de que la estabilidad monetaria de la zona euro se fundamenta en un control de los índices de déficit público y de la sostenibilidad financiera a la luz de los principios, los objetivos y los procedimientos contenidos en los artículos 121, 126 y 136 del TFUE.

Conforme al Protocolo $\mathrm{n}^{\mathrm{o}} .12$ anexo al TUE, sobre el procedimiento aplicable en caso de déficit excesivo, se establecieron los valores de referencia relativos al umbral 
máximo de déficit público para el conjunto de las AAPP de cada uno de los Estados miembros, que será del $3 \%$ del Producto Interior Bruto (en adelante, PIB) a precios de mercado; y, del $60 \%$ del PIB a precios de mercado respecto del nivel de deuda públi$c a$, de tal suerte que los Estados miembros que excedan los límites señalados deberán reducir su volumen de deuda «a un ritmo medio de una veinteava parte al año como referencia». De acuerdo con ello pues, se refuerza la supervisión económica y presupuestaria en orden a la consecución de la estabilidad financiera de los Estados miembros, que en consecuencia deberán corregir eventuales situaciones de déficit presupuestario excesivo. La «regla de equilibrio presupuestario» regulada en el artículo 3.1 del citado protocolo establece que: «la situación presupuestaria de las Administraciones Públicas de cada Parte Contratante será de equilibrio o superávit» (art. 3.1.a), de modo que: «en el caso de que se observen desviaciones significativas del objetivo a medio plazo o de la senda de ajuste hacia dicho objetivo, se activará automáticamente un mecanismo corrector» (art. 3.1.e).

Las reformas adoptadas a nivel europeo contextualizan las diferentes medidas aprobadas en el ámbito de las EELL españolas por cuanto las mismas quedan comprometidas en la consecución de los objetivos y los procedimientos en materia de control presupuestario. Las medidas adoptadas por parte de las AAPP españolas deben guardar observancia de la normativa europea y ejercer la consiguiente coordinación interadministrativa para el cumplimiento de las disposiciones comunitarias. En este sentido, el párrafo tercero del artículo 10 sobre las disposiciones para la aplicación efectiva de la Ley y mecanismos de coordinación de la LOEPSF regula la vigencia de los mecanismos derivados del principio de coordinación entre todas las AAPP en orden a la consecución de los principios de sostenibilidad financiera y estabilidad presupuestaria en «coherencia con la normativa europea» (art. 10.3, LOEPSF). En segundo lugar, resulta preciso evidenciar el régimen de sanciones que eventualmente pueden ser impuestas al Estado español como consecuencia del incumplimiento de las normas del Derecho europeo comunitario. Así, destacan las sanciones que eventualmente puedan atribuir, imputar y aplicar las instituciones europeas sobre el Estado español; los mecanismos de control y supervisión europeos; y, la necesaria remisión de información periódica a la Comisión Europea sobre el grado de cumplimiento de los objetivos de estabilidad presupuestaria, deuda pública y regla de gasto. En tercer lugar, las EELL quedan sujetas a los límites contenidos en la normativa europea sobre sostenibilidad financiera, así como a los límites o volumen y valor máximo de deuda pública, debiéndose adaptar las instituciones españolas a la metodología para el cálculo del déficit estructural y la tasa de crecimiento del PIB de medio plazo de la economía española, o la adopción del Sistema Europeo de Cuentas Nacionales y Regionales (SEC-95). Siendo la coordinación y la supervisión de la disciplina presupuestaria de los Estados miembros cuya moneda es el euro uno de los instrumentos para el correcto funcionamiento de la UEM, el artículo 126 del TFUE establece en su párrafo primero que «los Estados miembros evitarán déficits públicos excesivos» (art. 126.1). En este sentido, se encomienda a la Comisión la supervisión de «la evaluación de la situación presupuestaria y del nivel de endeudamiento público de los Estados miembros con el fin de detectar errores manifiestos» (art. 126.2 TFUE). En base a lo expuesto corresponde a las instituciones de la UE la observancia y el ejercicio de la disciplina presupuestaria 
en función de «la situación económica y presupuestaria a medio plazo del Estado miembro» (art. 126.3 TFUE). Junto con la situación de equilibrio presupuestario, la UE desarrolla el concepto de sostenibilidad financiera de las cuentas públicas entendida como «una situación del presupuesto sin un déficit público excesivo» (art. 140.1). Finalmente, el Estado español debe remitir de forma periódica la información precisa y detallada que permita a las instituciones comunitarias europeas verificar el cumplimiento de los objetivos de estabilidad presupuestaria y de consolidación fiscal por parte del conjunto de las AAPP españolas, con especial incidencia sobre las EELL.

En consecuencia, el proceso de integración del Estado español en la UE y en la UEM ha venido acompañado y ha supuesto a su vez un conjunto de reformas legislativas que afectando al conjunto de las AAPP españolas, han dotado de plena vigencia a los principios de estabilidad presupuestaria y sostenibilidad financiera sobre las EELL. La propia LOEPSF recalca la importancia de la normativa europea disponiendo que sea el Gobierno quien implante los mecanismos de coordinación entre el conjunto de las AAPP para garantizar el cumplimiento de los principios de estabilidad presupuestaria y sostenibilidad financiera en coherencia con las disposiciones europeas.

A la luz de la normativa comunitaria europea expuesta y como consecuencia del pacto político alcanzado por el PSOE (en el gobierno) y el PP (principal partido de la oposición) a lo largo de los meses de agosto y septiembre del año 2011, se procedió a la reforma del artículo $135 \mathrm{CE}^{15}$ conforme a la literalidad comparativa contenida en la Tabla 1. La reforma del artículo $135 \mathrm{CE}$ representa el hito institucional clave que incidirá e informará el conjunto de la subsiguiente normativa relativa a la sostenibilidad financiera del conjunto de las AAPP españolas. La reforma aprobada se incardina en el mandato europeo dirigido a garantizar la transposición de las normas y las reglas de sostenibilidad financiera y estabilidad presupuestaria, constituyendo una exigencia de la UE contenida en el TECGUEM (Pacto Fiscal Europeo) por la que se insta a los Estados miembros (Partes Contratantes) a que adopten: «disposiciones que tengan fuerza vinculante y sean de carácter permanente, preferentemente de rango constitucional, a cuyo respeto y cumplimiento estén de otro modo plenamente garantizadas a lo largo de los procedimientos presupuestarios nacionales» (art. 3.2). De acuerdo con GarcíaEscudero Márquez, en la Exposición de Motivos de la reforma del artículo $135 \mathrm{CE}$ : «se cita también el Pacto de Estabilidad y Crecimiento y el objetivo de reforzar el compromiso de España con la Unión Europea. No es sino el reconocimiento de un condicionamiento exterior del poder constituyente del Estado, inherente, como dice Rubio Llorente, a la integración europea» (García-Escudero Márquez, 2013). De esta forma y por consiguiente: «el marco constitucional de las Haciendas españolas es actualmente interno y comunitario» (Navarro Fauré, 2013).

15 Aprobación el 2 de septiembre de 2011, por el procedimiento de lectura única, de la proposición de reforma del artículo 135 de la Constitución española, presentada por los grupos parlamentarios Socialista y Popular en el Congreso. «BOCG. Congreso de los Diputados», serie B, número 329-1, de 26 de agosto de 2011 . 


\section{Tabla 1. Reforma del artículo 135 CE}

\begin{tabular}{|c|c|}
\hline $\begin{array}{l}\text { Redacción del artículo } 135 \\
\text { CE previo a la reforma del } \\
\text { año } 2011\end{array}$ & Redacción del artículo 135 CE resultante de la reforma del año 2011 \\
\hline $\begin{array}{l}\text { 1. El Gobierno habrá de estar } \\
\text { autorizado por ley para emitir } \\
\text { Deuda Pública o contraer cré- } \\
\text { dito. } \\
\text { 2. Los créditos para satisfacer } \\
\text { el pago de intereses y capital } \\
\text { de la Deuda Pública del Esta- } \\
\text { do se entenderán siempre } \\
\text { incluidos en el estado de gas- } \\
\text { tos de los presupuestos y no } \\
\text { podrán ser objeto de enmien- } \\
\text { da o modificación, mientras } \\
\text { se ajusten a las condiciones } \\
\text { de la ley de emisión. }\end{array}$ & 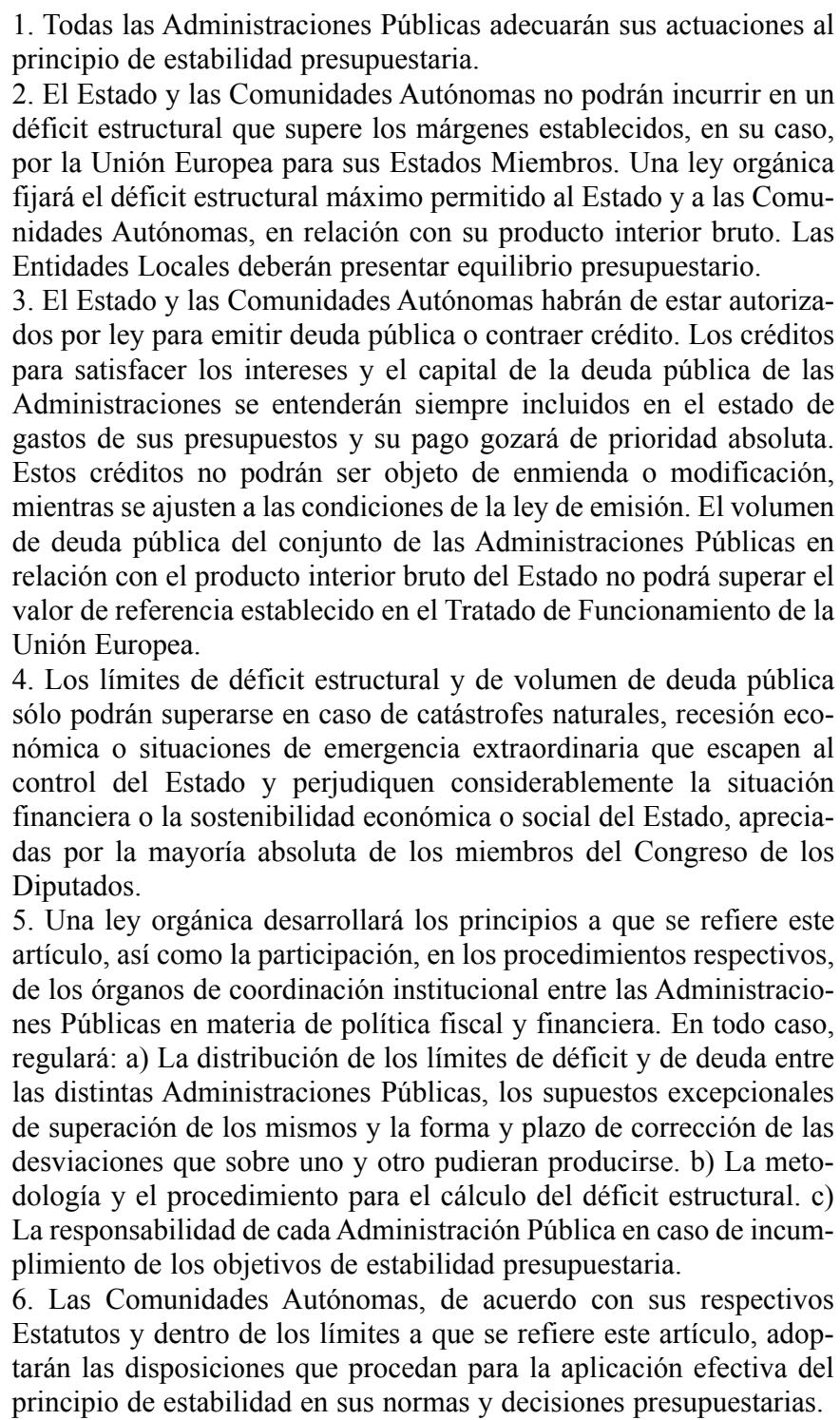 \\
\hline
\end{tabular}

Fuente: reforma del artículo 135 de la Constitución Española, de 27 de septiembre de 2011 (BOE núm. 233 , de 27 de septiembre de 2011, páginas 101931 a 101941). 


\subsection{Los efectos y el impacto de las reformas presupuestarias de control del déficit público sobre las relaciones interadministrativas entre el Estado y las EELL}

Las principales normas que cabría enumerar por su incidencia en el régimen de los controles y las autorizaciones de contenido económico-financiero sobre las EELL han sido con carácter cronológico (2008-2014) y entre otras, las siguientes: el Real Decreto-ley 9/2008, de 28 de noviembre, por el que se crea un Fondo Estatal de Inversión Local y un Fondo Especial del Estado para la Dinamización de la Economía y el Empleo; el Real Decreto-ley 8/2010, de 20 de mayo, por el que se adoptan medidas extraordinarias para la reducción del déficit público; la Reforma del artículo 135 de la Constitución Española, de 27 de septiembre de 2011, en los términos expuestos en los párrafos precedentes; la Ley Orgánica 2/2012, de 27 de abril, de Estabilidad Presupuestaria y Sostenibilidad Financiera ${ }^{16}$, por medio de la que se regula la estabilidad presupuestaria y la sostenibilidad financiera para el conjunto de las AAPP y de la Seguridad Social en general, y de las EELL en particular. De acuerdo con el preámbulo de la misma, se persigue la consecución de una: «mayor coordinación, vigilancia y supervisión en materia presupuestaria» (Preámbulo, LOEPSF); la Ley 19/2013, de 9 de diciembre, de transparencia, acceso a la información pública y buen gobierno, en la cual se «clarifica y refuerza el régimen sancionador» en orden a la aplicación de los principios éticos y de actuación vigentes para los altos cargos y asimilados de las EELL, tipificando un catálogo de infracciones disciplinarias y sanciones asociadas en materia de gestión económico-presupuestaria; los planes o mecanismos de financiación pública para el pago a proveedores por parte de las EELL, a través de los siguientes Reales-Decretos ley: el Real Decreto-ley 5/2009, de 24 de abril, de medidas extraordinarias y urgentes para facilitar a las entidades locales el saneamiento de deudas pendientes de pago con empresas y autónomos; el Real Decreto-ley 8/2011, de 1 de julio, de medidas de apoyo a los deudores hipotecarios, de control del gasto público y cancelación de deudas con empresas y autónomos contraídas por las entidades locales, de fomento de la actividad empresarial e impulso de la rehabilitación y de simplificación administrativa; el Real Decreto-ley 4/2012, de 24 de febrero, por el que se determinan obligaciones de información y procedimientos necesarios para establecer

16 Conforme a la reforma del mismo en septiembre del año 2011, el artículo 135 CE establece en su párrafo quinto que: «una ley orgánica desarrollará los principios a que se refiere este artículo, así como la participación, en los procedimientos respectivos, de los órganos de coordinación institucional entre las AAPP en materia de política fiscal y financiera. En todo caso, regulará: a) La distribución de los límites de déficit y de deuda entre las distintas Administraciones Públicas, los supuestos excepcionales de superación de los mismos y la forma y plazo de corrección de las desviaciones que sobre uno y otro pudieran producirse. b) La metodología y el procedimiento para el cálculo del déficit estructural. c) La responsabilidad de cada Administración Pública en caso de incumplimiento de los objetivos de estabilidad presupuestaria». La disposición adicional única de la reforma, según su publicación en el Boletín Oficial del Estado (BOE) el 27 de septiembre de 2011, mandata lo siguiente: «1. La Ley Orgánica prevista en el artículo 135 de la Constitución Española deberá estar aprobada antes de 30 de junio de 2012. 2. Dicha ley contemplará los mecanismos que permitan el cumplimiento del límite de deuda a que se refiere el artículo 135.3». 
un mecanismo de financiación para el pago a los proveedores de las entidades locales; y, el real Decreto-ley 7/2012, de 9 de marzo, por el que se crea el Fondo para la financiación de los pagos a proveedores; y finalmente, la Ley 27/2013, de 27 de diciembre, de racionalización y sostenibilidad de la Administración Local.

A continuación, se expone el análisis integrado de las normas señaladas, evaluando su impacto sobre las principales dimensiones a través de las cuales se ha manifestado el incremento y el refuerzo de los controles de tutela presupuestaria y financiera sobre las EELL por parte de los organismos e instituciones estatales. Para ello se agrupan los resultados de dichos cambios en los siguientes bloques o ámbitos; a saber: 1) el régimen de autorización de las operaciones de crédito; 2) el control y el cumplimiento forzoso de las medidas de sostenibilidad financiera y estabilidad presupuestaria de las EELL; 3) la necesidad de informar a los organismos del Estado (Ministerio de Hacienda y Administraciones Públicas); y, 4) las responsabilidades de los funcionarios de Administración Local con habilitación estatal en el control de la gestión presupuestaria y la consecución de la sostenibilidad financiera de las EELL.

\subsubsection{El régimen de autorización de las operaciones de crédito}

La activación del endeudamiento como una de las fuentes o recursos de financiación destinados a liquidar las obligaciones pendientes de pago a los contratistas ${ }^{17}$, implicó - de acuerdo con lo evidenciado por la Tabla 2- un incremento de la Deuda Viva de las EELL y un acrecentamiento del recurso a los mecanismos de endeudamiento a nivel local, con la consiguiente incidencia del régimen de autorización ligado a las operaciones de crédito suscritas o concertadas. Así, como consecuencia de la implementación de los diferentes mecanismos o Planes de Pago a Proveedores, se producirá un aumento de los gastos financieros adscritos a los intereses de los préstamos suscritos por una cuantía de $1.512 .000 .000 €$ en 2012 y de $1.680 .000 .000 €$ en 2013, así como debido al Fondo de Contingencia previsto en la LOEPSF (126.000.000 €). No obstante y con carácter previo, la Deuda Viva comenzó a registrar incrementos significativos a partir de la secuencia temporal que se iniciaría en el año 2009, en coincidencia con la adopción de los sucesivos instrumentos de pago a proveedores y la caída de los ingresos tributarios de las EELL.

17 Las cuales deberán reunir, a la luz del artículo 2.1 del Real Decreto-ley 4/2012, de 24 de febrero, por el que se determinan obligaciones de información y procedimientos necesarios para establecer un mecanismo de financiación para el pago a los proveedores de las entidades locales, los siguientes requisitos: a) Ser vencidas, líquidas y exigibles; b) Que la recepción, en el registro administrativo de la entidad local, de la correspondiente factura, factura rectificativa en su caso, o solicitud de pago equivalente haya tenido lugar antes del 1 de enero de 2012; y, c) Que se trate de contratos de obras, servicios o suministros incluidos en el ámbito de aplicación del texto refundido de la Ley de Contratos del Sector Público aprobado por el Real Decreto Legislativo 3/2011, de 14 de noviembre. 
Tabla 2. Resumen de la Deuda Viva de las Entidades Locales

\begin{tabular}{|c|c|c|c|c|c|c|}
\hline & Ayuntamientos & $\begin{array}{c}\text { Diputaciones, } \\
\text { Consejos } \\
\text { y Cabildos } \\
\text { Insulares }\end{array}$ & $\begin{array}{c}\text { Entidades } \\
\text { Locales } \\
\text { Menores y } \\
\text { Mancomunidades }\end{array}$ & TOTAL & $\begin{array}{c}\text { Diferencia } \\
\text { porcentual } \\
\text { interanual (\%) }\end{array}$ & $\begin{array}{c}\text { Diferencia } \\
\text { porcentual } \\
(2008-2013) \\
(\%)\end{array}$ \\
\hline 2008 & 26.128 .00 & 5.902 .233 & - & 32.030 .233 & - & \\
\cline { 1 - 6 } 2009 & 28.770 .000 & 5.825 .000 & - & 34.595 .000 & +8.00 & \multirow{2}{*}{+29.49} \\
\hline 2010 & 28.851 .530 & 6.358 .000 & 233.844 & 35.443 .374 & +2.45 & \\
\cline { 1 - 5 } 2011 & 28.460 .645 & 6.732 .267 & 226.856 & 35.419 .768 & -0.07 & \\
\hline 2012 & 35.290 .059 & 6.442 .548 & 206.693 & 41.939 .299 & +18.41 & \\
\hline 2013 & 35.090 .411 & 5.994 .894 & 394.327 & 41.476 .632 & -1.10 & \\
\hline
\end{tabular}

Elaboración propia. Fuente: Ministerio de Hacienda y Administraciones Públicas (datos en miles de euros)

De forma paralela, el déficit de las EELL españolas mostrará un descenso de 0.3 puntos porcentuales durante el año 2012, alcanzando de este modo el $0.15 \%$ del PIB (sobre el $0.3 \%$ establecido como límite para las mismas). A pesar de la caída de los ingresos en un $2.4 \%$ y aún con un aumento impositivo del $2.1 \%$, los gastos se redujeron en un $12.1 \%$ (imputable fundamentalmente al descenso de las inversiones). Para el año 2013 las EELL alcanzaron una situación de superávit del $0.41 \%$ sobre el PIB $^{18}$.

El desplome de los ingresos de las EELL, fuertemente vinculados a la recaudación asociada al sector de la construcción, supuso la acumulación de obligaciones pendientes de pago a cargo de las mismas habiendo sido contraídas con sus proveedores y no satisfechas o canceladas ante la falta de la suficiente liquidez y la necesidad de garantizar su financiación. La dependencia tributaria respecto del sector inmobiliario y de la construcción ha sido definido como un factor estructural ligado a la crónica insuficiencia financiera de las EELL: «lo cual determina que muchas de éstas obtengan la mayor parte de sus recursos de la expedición de licencias de obras» (Almeida Cerreda, 2008). El presente trabajo se contextualiza en un escenario de: «una situación cró-

${ }^{18}$ La implementación de los planes de ajuste, junto con el ahorro previsto a través de la reforma del régimen local -por medio de la LRSAL-, arrojan el siguiente impacto futuro estimado de las citadas medidas sobre las EELL (ver Tabla 3. Proyecciones sobre el impacto de la reforma local y los planes de ajuste en el balance de las cuentas públicas de las EELL medidas por su efecto diferencial respecto al año anterior).

\begin{tabular}{|c|c|c|c|c|}
\hline & 2012 & 2013 & 2014 & 2015 \\
\hline Reforma local y planes de ajuste & 0.1 & 0.2 & 0.3 & 0.5 \\
\hline
\end{tabular}

Fuente: Programa de Estabilidad del Reino de España (2013 - 2016). 
nica de insuficiencia y precariedad financieras» (Ramos Prieto, 2003) de las EELL. La recesión económica a partir del año 2008 se manifestará con un impacto significativo sobre las cuentas públicas locales, no sólo por el incremento de los gastos que supondrá la creciente demanda de protección social, sino por la fluctuación generalizada de la economía y la caída en los índices de la recaudación con el consiguiente efecto presupuestario. La secuencia de los distintos mecanismos de financiación dará comienzo con la aprobación del Real Decreto-ley 9/2008, de 28 de noviembre, por el que se crean un Fondo Estatal de Inversión Local y un Fondo Especial del Estado para la Dinamización de la Economía y el Empleo y se aprueban créditos extraordinarios para atender a su financiación, en el marco del Plan Español para el Estímulo de la Economía y el Empleo. Esta norma constituye la preliminar medida adoptada en orden a atender las dificultades que de forma especial vendrían a experimentar las EELL desde la perspectiva presupuestaria, al socaire de la caída de los ingresos tributarios como consecuencia de la dependencia de los mismos con respecto al sector urbanístico.

De acuerdo con Pérez López et al.: «la especial situación de crisis económica, junto con las restricciones al endeudamiento impuestas a los ayuntamientos y el control del déficit público, han reducido los recursos de las administraciones locales» (Pérez López \& Plata Díaz, 2013). De hecho, y en este sentido la propia Exposición de Motivos del citado Real Decreto-ley 9/2008, de 28 de noviembre, destacaba la importancia específica del Fondo en base a su contribución destinada a favorecer: «(...) la viabilidad y el empleo de pequeñas y medianas empresas que centran sus actividades en áreas anexas a la construcción, como los servicios de ingeniería, arquitectura, logística, así como la producción y movilización de materiales, maquinaria y equipamiento diverso». La autorización para la realización de los proyectos que vendrían a financiarse con cargo al popularmente conocido como «Plan E» se realizarían bajo la responsabilidad del Ministerio de Hacienda y Administraciones Públicas, por medio de cuya Secretaría de Estado de Cooperación Territorial se otorgarían los correspondientes créditos.

Con el propósito de afrontar la situación de crisis financiera de las EELL, el último de los mecanismos de financiación de las EELL aprobados vino dado por el Plan de Pago a Proveedores del año 2012, al cual se adhirieron un total de 3.777 EELL, abonando 1.796.696 facturas por un importe de 9.598.340,50 $€$ a 114.935 proveedores. Durante el año 2013 el Fondo de Proveedores contempló un total de 1.965.080,95 € en favor de las EELL. Por medio del Real Decreto-ley 8/2014, de 4 de julio, de aprobación de medidas urgentes para el crecimiento, la competitividad y la eficiencia: «las EELL podrán concertar nuevas operaciones de endeudamiento para cancelar parcial o totalmente su deuda pendiente con el Fondo para la Financiación de los Pagos a Proveedores». Si bien, las EELL que se adhieran a tal recurso deberán contar con la preceptiva autorización del Ministerio de Hacienda y Administraciones Públicas.

En lo correspondiente a las medidas que de forma específica involucran a las EELL en la consecución de la consolidación físcal, así como en el incremento del control sobre las mismas en materia económica y financiera, el capítulo VI del Real Decretoley $8 / 2010$, de 20 de mayo, dedicado a las «medidas en materia económico financiera de las entidades locales», afecta el destino de los fondos resultantes del ahorro a las siguientes finalidades (y con el enumerado orden de prelación según sigue); a saber: a 
sanear el remanente de tesorería derivado de la última liquidación, cuando éste fuera negativo; a disminuir el nivel de endeudamiento a largo plazo; y, a la financiación de inversiones (art. 14.1).

Así pues, una de las expresiones o manifestaciones concretas de las relaciones de dependencia o tutela ejercida por el Estado sobre las EELL que mayor importancia ha adquirido a lo largo de los últimos años a la luz de las reformas adoptadas, ha venido dada por el incremento de los controles ligados a la necesaria y preceptiva autorización para la concertación de operaciones de crédito a largo plazo, en tanto que acto administrativo de ejecución requerido bajo determinados supuestos y circunstancias, y que han emplazado al Estado «en una posición de superioridad respecto de las EELL» (Alonso Higuera, 2002). El propio Programa de Estabilidad del Reino de España (2013-2016), destaca cómo en el contexto de las sucesivas medidas aprobadas: «(...) se habilita al Gobierno para establecer las normas sobre los procedimientos de control» con el propósito de armonizar la política crediticia del conjunto de las EELL. El Estado es el encargado en este sentido, en los límites variables de la Autonomía Financiera de las EELL, de velar por el cumplimiento de los principios de estabilidad presupuestaria, sostenibilidad financiera, plurianualidad, transparencia, eficiencia en la asignación y utilización de los recursos públicos, responsabilidad y lealtad institucional.

Una de las fuentes de financiación de las EELL viene dada por el recurso a las operaciones de crédito en virtud de su autonomía (limitada y tutelada) para el acceso al endeudamiento. La concertación de operaciones de crédito, junto con el conjunto de los recursos tributarios, dota de contenido a la autonomía financiera local en el ámbito de los ingresos. Tras la refundición de las normas reguladoras del régimen presupuestario y tributario de las Haciendas Locales ${ }^{19}$ por medio del Real Decreto Legislativo $2 / 2004$, de 5 de marzo, por el que se aprueba el texto refundido de la Ley Reguladora de las Haciendas Locales, el artículo 2.1.f articula como uno de los recursos de las EELL, «el producto de las operaciones de crédito». La concertación de las operaciones de crédito corresponde al alcalde ${ }^{20}$, así como al Pleno del Ayuntamiento la concertación de aquellas «operaciones de crédito cuya cuantía acumulada, dentro de cada ejercicio económico, exceda del 10 por ciento de los recursos ordinarios del Presupuesto (salvo las de tesorería, que le corresponderán cuando el importe acumulado de las operaciones vivas en cada momento supere el 15 por ciento de los ingresos corrientes liquidados en el ejercicio anterior) todo ello de conformidad con lo dispuesto en la LRHL» (art. 22.2.m, LRBRL). Tales operaciones serán suscritas con el voto favorable

${ }_{19}$ Cabe destacar, entre las disposiciones previas al Real Decreto Legislativo 2/2004, de 5 de marzo, la Ley 39/1988, de 28 de diciembre, reguladora de las Haciendas Locales, y la Ley 51/2002, de 27 de diciembre, de reforma de la Ley 39/1988, de 28 de diciembre, reguladora de las Haciendas Locales.

20 «Con exclusión de las contempladas en el artículo 158.5 de la Ley 39/1988, de 28 de diciembre, Reguladora de las Haciendas Locales, siempre que aquéllas estén previstas en el Presupuesto y su importe acumulado dentro de cada ejercicio económico no supere el 10 por ciento de sus recursos ordinarios, salvo las de tesorería que le corresponderán cuando el importe acumulado de las operaciones vivas en cada momento no supere el 15 por ciento de los ingresos corrientes liquidados en el ejercicio anterior, ordenar pagos y rendir cuentas ; todo ello de conformidad con lo dispuesto en la Ley Reguladora de las Haciendas Locales» (art. 21.1.f., Ley 7/1985, de 2 de abril, Reguladora de las Bases del Régimen Local). 
de la mayoría absoluta del número legal de miembros de la Corporación (art. 47.2, Ley 7/1985, de 2 de abril, Reguladora de las Bases del Régimen Local), que será igualmente requerida para la suscripción de las operaciones de crédito reguladas por el artículo 158.5 de la Ley 39/1988, de 28 de diciembre, reguladora de las Haciendas Locales (art. 47.2.1 LRBRL). El régimen de concertación de las operaciones de crédito, tanto a corto como a largo plazo, así como las «operaciones financieras de cobertura y gestión del riesgo del tipo de interés y del tipo de cambio» (art. 48), se regula en el conjunto de los artículos 48 a 55 (ambos incluidos) que compendian el Capítulo VII (operaciones de crédito) de la citada norma reguladora de las Haciendas Locales. Desde el año 2010, a partir del Real Decreto-ley 8/2010, de 20 de mayo, por el que se adoptan medidas extraordinarias para la reducción del déficit público, y fundamentalmente a partir del año 2012, se han aprobado un conjunto de normas que han supuesto una significativa transformación del régimen de relaciones interadministrativas multinivel relacionadas con la financiación local y el control del déficit y la sostenibilidad financiera de las EELL.

La transposición de los criterios de convergencia europea conforme al artículo 109 del Tratado Constitutivo de la Comunidad Europea supondrá la atribución en favor del Estado de un extenso y exhaustivo catálogo de mecanismos de tutela financiera. Al amparo de tal circunstancia y a partir de la entrada en vigor de la Ley 50/1998, de 30 de diciembre, de Medidas Fiscales, Administrativas y del Orden Social, las EELL no precisarán de la preceptiva autorización administrativa que de manera generalizada requerían para la concertación de operaciones de crédito, de tal forma que sólo será necesaria la misma cuando el capital vivo de la Entidad superase el $110 \%$ de los recursos liquidados por la misma, o bien en caso de ahorro neto negativo. En este sentido, bajo el supuesto de que las obligaciones reconocidas sean superiores a los derechos liquidados (situación de ahorro neto negativo), las EELL están sujetas a la autorización preceptiva del Ministerio de Hacienda así como de la correspondiente Comunidad Autónoma (en caso que ésta tuviere reconocida y desarrollada legislativamente tal competencia) para concertar operaciones de crédito a largo plazo, con el requisito de aprobar un plan de ajuste o saneamiento financiero y presupuestario ${ }^{21}$. En tales casos, el criterio que de manera preferente será tenido en consideración por el órgano autorizante para la concesión afirmativa de dicha autorización, vendrá dado por el cumplimiento (o inobservancia, en su caso) del principio de estabilidad presupuestaria en los términos desarrollados en la Ley General de Estabilidad Presupuestaria. En caso de no cumplir satisfactoriamente tales límites y términos de deuda viva y ahorro neto así como de situación económica (remanente de tesorería principalmente, entre otras magnitudes financieras), la autorización estará condicionada a la elaboración y aprobación de un plan económico-financiero de reequilibrio durante el período de amortización del crédito. En términos generales pues, y: «salvo determinados casos que la ley espe-

${ }^{21}$ Además, de acuerdo con Navarro Fauré: «en todo caso se necesita autorización para las operaciones de crédito de cualquier clase que se formalicen en el exterior o con entidades financieras no residentes en España, o las que se instrumenten mediante emisiones de deuda o cualquier otra forma de apelación al crédito público» (Navarro Fauré, 2012). 
cífica, el endeudamiento de los municipios debe ser previamente autorizado por las autoridades del Ministerio estatal de Hacienda» (Vallès \& Brugué, 2001).

La Ley 19/2013, de 9 de diciembre, de transparencia, acceso a la información pública y buen gobierno, en el catálogo de infracciones en materia de gestión económico-financiera, tipifica como muy grave: «la realización de operaciones de crédito y emisiones de deudas que no cuenten con la preceptiva autorización o, habiéndola obtenido, no se cumpla con lo en ella previsto o se superen los límites previstos en la LOEPSF, de Financiación de las Comunidades Autónomas, y en el Texto Refundido de la Ley Reguladora de las Haciendas Locales, aprobado por el Real Decreto Legislativo 2/2004, de 5 de marzo» (artículo 28.g). La consecuencia derivada de la comisión de una infracción muy grave supondrá la destitución: «del cargo que ocupen salvo que ya hubiesen cesado y no podrán ser nombrados para ocupar ningún puesto de alto cargo o asimilado durante un período de entre cinco y diez años (...)» (artículo 30.4). En cualquier caso, de acuerdo con el artículo 30.2 de la Ley 19/2013, de 9 de diciembre, de transparencia, acceso a la información pública y buen gobierno, las sanciones ligadas a una infracción muy grave serán: «1. La declaración del incumplimiento y su publicación en el BOE o diario oficial que corresponda; 2) La no percepción, en el caso de que la llevara aparejada, de la correspondiente indemnización para el caso de cese en el cargo» (art. 30.2) $)^{22}$.

En base a lo establecido en el artículo 13 LOEPSF (instrumentación del principio de sostenibilidad financiera): «la autorización del Estado, o en su caso de las CCAA, a las Corporaciones Locales para realizar operaciones de crédito y emisiones de deuda, en cumplimiento de lo establecido en el artículo 53 del Texto Refundido de la Ley Reguladora de las Haciendas Locales, aprobada por Real Decreto Legislativo 2/2004, de 5 de marzo, tendrá en cuenta el cumplimiento de los objetivos de estabilidad presupuestaria y de deuda pública, así como al cumplimiento de los principios y las obligaciones que se derivan de la aplicación de esta Ley» (art. 13). Además de los supuestos establecidos y como parte de las medidas automáticas de corrección contempladas en el artículo 20.2 de la LO 2/2012, de 27 de abril: «en los supuestos de incumplimiento del objetivo de estabilidad presupuestaria o de deuda pública de las Corporaciones Locales incluidas en el ámbito subjetivo definido en los artículos 111 y 135 del Texto Refundido de la Ley Reguladora de las Haciendas Locales, todas las operaciones de endeudamiento a largo plazo de la corporación local incumplidora, precisarán autorización del Estado o en su caso de la Comunidad Autónoma que tenga atribuida la tutela financiera» (art. 20.2).

Además, el Ministerio de Hacienda y Administraciones Públicas no autorizará ninguna operación de crédito en el caso de que las EELL incumplan la obligación de aprobar un plan económico-financiero bajo los supuestos requeridos (art. 25.2, LOEPSF). En este sentido, la actuación de las EELL ha quedado claramente sujeta a nuevos controles que entre otras áreas o ámbitos de gestión (tales como el personal, el gasto corriente, las

22 «Cuando los presuntos responsables sean personas al servicio de la Administración autonómica o local, la orden de incoación del procedimiento se dará por los órganos que tengan atribuidas estas funciones en aplicación del régimen disciplinario propio de las Comunidades Autónomas o Entidades Locales en las que presten servicios los órganos contra los que se dirige el procedimiento» (art. 31.2. c). 
inversiones o la contratación), han incidido de forma especial en la restricción de las condiciones para el acceso al endeudamiento. La reducción de la morosidad y la contención del gasto público devienen en el fundamento legitimador de las disposiciones señaladas. Hasta tal punto, durante el período comprendido entre la entrada en vigor del Real Decreto-ley $8 / 2010$, de 20 de mayo, por el que se adoptan medidas extraordinarias para la reducción del déficit público, y hasta el 31 de diciembre de 2011: «las entidades locales y sus entidades dependientes clasificadas en el sector Administraciones Públicas no podrán acudir al crédito público o privado a largo plazo, en cualquiera de sus modalidades, para la financiación de sus inversiones, ni sustituir total o parcialmente operaciones preexistentes, a excepción de aquellas que en términos de valor actual neto resulten beneficiosas para la entidad por disminuir la carga financiera, el plazo de amortización o ambos» (art. 14.2) ${ }^{23}$. De este modo, la normativa ha venido a fortalecer: «el papel controlador del Ministerio de Hacienda (Administración que, en la mayor parte de los casos, ejerce la tutela financiera) asignándole facultades de informe vinculante y autorización sobre decisiones propias de la autoorganización local (competencias impropias, gestión coordinada)» (Villar Rojas, 2014) ${ }^{24}$.

Finalmente, la posibilidad de que las EELL cancelen (o refinancien) total o parcialmente su deuda con el Fondo para la Financiación de los Pago a Proveedores ${ }^{25}$ en el año 2014, suscribiendo nuevas operaciones de endeudamiento, queda sujeta a la autorización del Ministerio de Hacienda y Administraciones Públicas, que las valorizará en función de un plan de saneamiento financiero elaborado por la correspondiente Entidad Local, cuyo incumplimiento supondrá la imposibilidad de concertar operaciones de crédito a largo plazo. Tales Planes de saneamiento o de reducción de deuda estarán sometidos a las siguientes condiciones (ver Tabla 4):

${ }^{23}$ En este sentido, la propia Comisión Ejecutiva de la FEMP aprobó por unanimidad, solicitar la eliminación de los límites de endeudamiento para el año 2011: «para los proyectos ya iniciados, los cofinanciados con otras instituciones u organismos autónomos y los que tengan carácter plurianual, así como los gastos de reposición, establecida en el Real Decreto sobre reducción del déficit público» (FEMP, 2011).

${ }^{24}$ En la medida en que la capacidad para la libre concertación de créditos por parte de las EELL se ve limitada por el carácter crecientemente restrictivo de la preceptiva autorización de otros niveles de gobierno (véase el estatal), comprometiendo eventualmente de esta forma el margen de decisión de los actores políticos y sociales en la libre participación y diseño de las líneas presupuestarias de la comunidad local, cabe alegar el impacto de la regulación analizada sobre el principio de la Autonomía Local. De este modo, se puede llegar a comprometer la capacidad de lo que la Carta Europea de la Autonomía Local ha denominado como las Asambleas y los Consejos representativos, a los que en base al principio democrático, corresponde decidir el destino de los recursos -incluidos los económicos y financieros- que permitan la realización de los proyectos y las inversiones consideras de interés, de manera deliberativa, por parte de los órganos «integrados por miembros elegidos por sufragio libre, secreto, igual, directo y universal», y por las asambleas de vecinos, el referéndum o «cualquiera otra forma de participación directa de los ciudadanos» (art. 3.2 de la Carta Europea de la Autonomía Local».

25 En este sentido, podrán refinanciarse, no sólo las operaciones formalizadas en aplicación del Real Decreto-ley 4/2012, de 24 de febrero, por el que se determinan obligaciones de información y procedimientos necesarios para establecer un mecanismo de financiación para el pago a los proveedores de las entidades locales, sino también las del Real Decreto-ley 5/2009, de 24 de abril, de medidas extraordinarias y urgentes para facilitar a las Entidades Locales el saneamiento de deudas pendientes de pago con empresas y autónomos. 
Tabla 4. Planes de saneamiento financiero y/o reducción de deuda

\begin{tabular}{|l|c|c|}
\hline \multicolumn{1}{|c|}{ Elaboración de Planes } & Ahorro Neto & Deuda Viva \% \\
\hline No necesario & + & $<75$ \\
\hline Plan Reducción Deuda & + & $75-110$ \\
\hline$-75 \%$ & + & $>110$ \\
\hline Plan Reducción Deuda -110\% & - & $<75$ \\
\hline Plan Saneamiento & - & $75-110$ \\
\hline Plan Saneamiento y reducción deuda $-75 \%$ & - & $>110$ \\
\hline Plan Saneamiento y reducción deuda $-10 \%$ & + & \\
\hline
\end{tabular}

Fuente: Ministerio de Hacienda y Administraciones Públicas.

El control y el cumplimiento forzoso de las medidas para la sostenibilidad financiera y la estabilidad presupuestaria de las EELL.

A las medidas de autorización y de tutela financiera expuestas cabe añadir los instrumentos o medidas correctivas establecidas por la LOEPSF, como consecuencia de los supuestos en los que concurra un incumplimiento de: 1) la estabilidad presupuestaria; 2) del objetivo de deuda pública; $\mathrm{o}, 3$ ) de la regla de gasto, debiéndose formular en tales casos un plan económico-financiero para la restitución de tales contravenciones. La LOEPSF mandata el necesario cumplimiento y mantenimiento de una posición de equilibrio o superávit presupuestario por parte de las EELL (artículo 11.4).

En primer lugar, cabe señalar que previamente a la aprobación de la LOEPSF sólo el Estado estaba sujeto con carácter obligatorio a la presentación y el cumplimiento de un límite de gasto como parámetro prioritario en la planificación presupuestaria de cada anualidad. Si bien, tal obligatoriedad se extenderá a las Corporaciones Locales (así como a las CCAA), las cuales deberán constituir un fondo de contingencia con objeto de atender las necesidades imprevistas y no discrecionales. En concreto, de acuerdo con el artículo 12 (regla de gasto) de la citada Ley, la variación del gasto computable de las Corporaciones Locales «no podrá superar la tasa de referencia de crecimiento del PIB de medio plazo de la economía española» (art. 12) ${ }^{26}$. A la hora de elaborar sus Presupuestos, las EELL deberán tener en cuenta la referencia de crecimiento del PIB de medio plazo de la economía española de acuerdo con el cálculo realiza-

${ }^{26}$ Conforme a la Exposición de Motivos de la Ley Orgánica 2/2012: «como novedad importante, la Ley extiende la obligación de presentar un límite de gasto, hasta ahora solo previsto para el Estado, a las Comunidades Autónomas y a las Corporaciones Locales, así como la dotación en sus Presupuestos de un fondo de contingencia para atender necesidades imprevistas y no discrecionales. Por último, se regula el destino del superávit presupuestario, que deberá aplicarse a la reducción de endeudamiento neto, o al Fondo de Reserva en el caso de la Seguridad Social» (Exposición de Motivos). 
do por el Ministerio competente, conforme a la metodología utilizada por la Comisión Europea. Si bien, y en orden a respetar la autonomía financiera de las EELL, la competencia del Gobierno para aprobar y establecer los objetivos de estabilidad presupuestaria y de deuda pública para el conjunto de las AAPP está sujeta a los instrumentos de coordinación entre el Estado y las EELL. Así pues, los objetivos de estabilidad presupuestaria y de deuda pública serán propuestos por el Gobierno (por medio del acuerdo del Consejo de Ministros), previo informe de la Comisión Nacional de Administración Local (art. 15.1, LOEPSF). De igual modo, el Ministro de Hacienda y Administraciones Públicas dirigirá informe anual a la Comisión Nacional de Administración Local respecto al grado de cumplimiento de los objetivos de estabilidad presupuestaria y de deuda pública (art. 17.4, LOEPSF).

Ahondando en los requerimientos de corrección de las situaciones de déficit contemplados en la normativa previa al año 2012, la LOEPSF incide en: «la posibilidad de imponer a las Corporaciones Locales medidas de cumplimiento forzoso, o disponer en su caso la disolución de la Corporación Local» (Exposición de Motivos) ${ }^{27}$. El Estado tendrá capacidad para la disolución de Ayuntamientos ${ }^{28} \mathrm{o}$ inhabilitar a los cargos públicos locales que incurran en un incumplimiento de las disposiciones sobre sostenibilidad presupuestaria y financiera. Las medidas de cumplimiento forzoso están dirigidas a legitimar la acción del Gobierno sobre una Corporación Local en caso de que la misma incumpla las obligaciones anteriormente detalladas (por no adoptar la no disponibilidad de créditos o la no constitución del depósito a que la Ley obliga), así como en caso de que desatendiese las propuestas de la comisión de expertos al efecto. En este sentido, se requerirá para que el Presidente de la Corporación Local adopte tales medidas, de tal suerte que el incumplimiento de dicha advertencia, y si de la misma se derivase un incumplimiento del objetivo de estabilidad presupuestaria, del objetivo de deuda pública o de la regla de gasto: «podrá considerarse como gestión gravemente dañosa para los intereses generales, y podrá procederse a la disolución de los órganos de la Corporación Local incumplidora, de conformidad con lo previsto en el artículo 61 de la Ley 7/1985, de 2 de abril, RBRL» (art. 26. Medidas de cumplimiento forzoso) ${ }^{29}$.

${ }^{27}$ La LOEPSF, en tanto que reguladora de la estabilidad presupuestaria y de la sostenibilidad financiera en el conjunto de las Administraciones Públicas, tiene plena vigencia sobre las EELL. De forma particular, y a diferencia de la normativa previa, dicha disposición legislativa reconocerá la capacidad plena de los organismos del Estado, para ejecutar medidas de forzoso cumplimiento o concluir la disolución de una Corporación Local, en caso de que por parte de la misma se dé un incumplimiento de las medidas automáticas de corrección del déficit público, y en concreto, de los planes económicos-financieros, lo cual conllevará la no disponibilidad de créditos y la constitución de un depósito.

${ }^{28}$ De este modo, junto al motivo de contribuir a la ejecución, el enaltecimiento o la justificación del terrorismo, y el menosprecio o humillación a las víctimas o a sus familiares, como constitutiva de una decisión gravemente dañosa para los intereses generales, se adiciona el del incumplimiento de aprobar un plan económico que afecte a la consecución de la estabilidad presupuestaria, el objetivo de deuda pública o la regla de gasto, constituyendo tal incumplimiento el fundamento causal para iniciar la disolución de los órganos de la Corporación Local, en tanto que medidas de forzoso cumplimiento.

${ }_{29}$ En la versión de 24 de mayo del año 2013 -finalmente no incluido ni aprobado definitivamente-, el texto de la propuesta de la Ley 27/2013, de 27 de diciembre, de racionalización y sostenibilidad de la Administración Local, llegó a contemplar, un primer párrafo del artículo 60, de acuerdo con el cual: «las 
En el caso expuesto, se establece un procedimiento para la elaboración, la aprobación y el seguimiento de los planes económico-financieros dirigidos a restituir las situaciones de desequilibrio presupuestario y financiero. Una vez detectada la situación de desequilibrio se deberá proceder a la aprobación por parte del Pleno de la Corporación de un plan económico-financiero por parte del Pleno de la correspondiente Cor-

corporaciones locales podrán ser intervenidas temporalmente con carácter previo a la disolución que se pudiera acordar de conformidad con lo previsto en el artículo 26.3 de la Ley Orgánica 2/2012, de 27 de abril, de Estabilidad Presupuestaria y Sostenibilidad Financiera». En la versión previa a fecha de 18 de febrero de 2013, el borrador incluía un detallado procedimiento de intervención de los ayuntamientos de menos de 5.000 habitantes, que tampoco fue finalmente aprobado. El texto incluía la siguiente literalidad: «artículo 61 bis. Intervención de Municipios con población inferior a 5.000 habitantes. 1. Los Municipios con población inferior a 5.000 habitantes que tengan en vigor un plan económico-financiero, serán intervenidos temporalmente cuando ocurra alguna de las siguientes circunstancias: a. Se haya procedido a la disolución del órgano de gobierno de la Corporación en aplicación de lo dispuesto en el apartado 3 del artículo 26 de la Ley Orgánica 2/2012, de 27 de abril, de Estabilidad Presupuestaria y Sostenibilidad Financiera. b. Superar el nivel de deuda permitido y no presentar el correspondiente plan de reducción de deuda o bien incumplir el mencionado plan, de acuerdo con lo previsto en la Ley Orgánica 2/2012, de 27 de abril, de Estabilidad Presupuestaria y Sostenibilidad Financiera, el texto refundido de la Ley Reguladora de las Haciendas Locales, aprobado por el Real Decreto Legislativo 2/2004, de 5 de marzo, y la Ley de Presupuestos Generales del Estado de cada año. c. Que su necesidad de financiación, en términos de contabilidad nacional, supere el cinco por cien de sus ingresos no financieros en dos ejercicios presupuestarios consecutivos. d. El incumplimiento reiterado de las obligaciones de remisión de información al Ministerio de Hacienda y Administraciones Públicas previstas en la Orden HAP/2105/2012, de 1 de octubre, por la que se desarrollan las obligaciones de suministro de información previstas en la Ley Orgánica 2/2012, de 27 de abril, de Estabilidad Presupuestaria y Sostenibilidad Financiera. A estos efectos, se entenderá que existe incumplimiento reiterado cuando se haya retenido durante tres meses consecutivos su participación en los ingresos del Estado, de conformidad con lo previsto en el artículo 36 de la Ley 2/2011, de 4 de marzo, de Economía Sostenible o bien, se hayan incumplido las obligaciones anuales de información durante dos años consecutivos, o las obligaciones trimestrales durante dos trimestres consecutivos, e. Cuando concurran todas las circunstancias siguientes: i. Haber obtenido una evaluación negativa de los servicios mínimos prestados por el ayuntamiento a los que se refiere el artículo 26. ii. Presenten en los tres años inmediatamente anteriores a la evaluación mencionada en la letra i) anterior remanentes de tesorería para gastos generales negativos. iii. Que el Municipio tengan retenido el porcentaje máximo permitido de su participación en los ingresos del Estado, de conformidad con lo dispuesto anualmente en la Ley de Presupuestos Generales del Estado. 2. El interventor del municipio o el órgano que ejerza la tutela financiera comunicará a la Diputación u órgano equivalente la concurrencia de lo previsto en el apartado primero. En el plazo máximo de un mes desde la recepción de esta comunicación, la Diputación, u órgano equivalente, adoptará por mayoría simple, previo informe del órgano que ejerza la tutela financiera, el acuerdo de intervención temporal del municipio. Transcurrido este plazo sin haberse adoptado el acuerdo se entenderá aprobado. 3. La adopción del acuerdo de intervención temporal conllevará que a partir de esa fecha los cargos electos de los órganos de gobierno del municipio dejarán de estar retribuidos y sólo la Diputación, u órgano equivalente: a. Será la competente para modificar y ejecutar el plan económico-financiero que tenga en vigor el municipio. b. Ejercerá todas las competencias del municipio necesarias para ejecutar el plan económico-financiero. c. Determinará el importe a partir del cual deben serle comunicados los compromisos de gasto con carácter previo a su asunción. Transcurridos quince días desde esta comunicación se entenderá autorizado el mencionado compromiso de gasto. d. Dará instrucciones al personal al servicio del Municipio temporalmente intervenido en ejercicio de lo previsto en este artículo. 4. El Municipio dejará de estar intervenido cuando cumpla el objetivo de estabilidad presupuestaria, el objetivo de deuda pública y la regla de gasto, previo informe favorable del órgano que ejerza la tutela financiera». 
poración Local, que será remitido al Ministerio de Hacienda y Administraciones Públicas, para su aprobación definitiva y su seguimiento. En relación al seguimiento de los mismos véase el procedimiento previsto en la Tabla 5 (artículo 24 LOEPSF):

\section{Tabla 5. Informes de seguimiento de los planes económico-financieros y de los planes de reequilibrio}

- La elaboración semestral de un informe de seguimiento por parte del Ministerio de Hacienda y Administraciones Públicas.

- Remisión de dichos informes a la Comisión Nacional de Administración Local, para el público conocimiento del seguimiento de los mismos.

- En caso de incumplimiento de los planes económicos-financieros, el Ministerio de Hacienda y Administraciones Públicas requerirá a las EELL correspondientes la justificación sobre la desviación operada, instará a la adopción de las medidas que garanticen el cumplimiento del objetivo de estabilidad, y si a pesar de tales advertencias, la Entidad Local persiste en el incumplimiento, se aplicarán las siguientes medidas coercitivas:

- Aprobación en el plazo de 15 días desde que se constate el incumplimiento «la no disponibilidad de créditos que garantice el cumplimiento del objetivo establecido» (art. 25.1).

- «Constituir un depósito con intereses en el Banco de España equivalente al 0,2 por ciento de su Producto Interior Bruto nominal. El depósito será cancelado en el momento en que se apliquen las medidas que garanticen el cumplimiento de los objetivos. Si en el plazo de 3 meses desde la constitución del depósito no se hubiera presentado o aprobado el plan, o no se hubieran aplicado las medidas, el depósito no devengará intereses. Si transcurrido un nuevo plazo de 3 meses persistiera el incumplimiento podrá acordar que el depósito se convertirá en multa coercitiva» (art. 25.1.b).

- En caso contrario: «el Gobierno podrá acordar el envío, bajo la dirección del Ministerio de Hacienda y Administraciones Públicas, de una comisión de expertos para valorar la situación económicopresupuestaria de la administración afectada. Esta comisión podrá solicitar, y la administración correspondiente estará obligada a facilitar, cualquier dato, información o antecedente respecto a las partidas de ingresos o gastos. La comisión deberá presentar una propuesta de medidas y sus conclusiones se harán públicas en una semana. Las medidas propuestas serán de obligado cumplimiento para la administración incumplidora» (art. 25.2).

En caso de que la Comunidad Autónoma correspondiente tenga atribuida la competencia de la tutela financiera sobre las EELL, el procedimiento será el siguiente:

- Remisión del plan a la Comunidad Autónoma.

- Aprobación y seguimiento por parte de la Comunidad Autónoma.

- La Comunidad Autónoma deberá remitir al Ministerio de Hacienda y Administraciones Públicas la información relativa a tales planes, así como del resultado de seguimiento de los mismos.

En cualquier caso: «Los planes económico-financieros se remitirán para su conocimiento a la Comisión Nacional de Administración Local. Se dará a estos planes la misma publicidad que la establecida por las leyes para los Presupuestos de la entidad» (art. 23.4, LO 2/2012, 27 de abril).

Finalmente, el Ministerio de Hacienda y Administraciones Públicas dará publicidad a los planes económico-financieros, a los planes de reequilibrio y a la adopción efectiva de las medidas aprobadas con un seguimiento del impacto efectivamente observado de las mismas. (art. 23.5, LO 2/2012, 27 de abril).

Fuente: artículo 24 LOEPSF. 
En cuanto al cumplimiento del objetivo de estabilidad presupuestaria, del objetivo de deuda pública o de la regla de gasto por parte de las EELL, constituye una infracción muy grave, de acuerdo con lo dispuesto en el artículo 28.h de la Ley 19/2013, de 9 de diciembre, de transparencia, acceso a la información pública y buen gobierno: «la no adopción en el plazo de las medidas necesarias para evitar el riesgo de incumplimiento, cuando se haya formulado la advertencia prevista en el artículo 19 LOEPSF $»^{30}$. En cualquier caso: «las Corporaciones Locales deberán mantener una posición de equilibrio o superávit presupuestario» (art. 11.4, LO 2/2012, de 27 de abril»). Respecto del control, seguimiento y cumplimiento de los Planes EconómicoFinancieros, constituye una infracción muy grave: «la no presentación o la falta de puesta en marcha en plazo del plan económico-financiero o del plan de reequilibrio de conformidad con el artículo 23 de la LOEPSF» (artículo 28. j); así como: «la falta de justificación de la desviación, o cuando así se lo haya requerido la falta de inclusión de nuevas medidas en el plan económico-financiero on en el plan de reequilibrio de acuerdo con el artículo 24.3 de la LOEPSF» (artículo 28. 1); o: «la no adopción de las medidas previstas en los planes económico-financieros y de reequilibrio, según corresponda, previstos en los artículos 21 y 22 de la LOEPSF» (artículo 28. m).

Por otra parte, los mayores y crecientes controles por parte del Estado sobre las EELL han venido como parte de las medidas de acompañamiento para el cumplimiento de los sucesivos mecanismos aprobados para dar apoyo a la liquidez de las Corporaciones Locales. En particular, la LOEPSF institucionaliza las medidas requeridas en caso de que una Entidad Local acuda a cualquier mecanismo extraordinario de apoyo a la liquidez al margen de los Planes previamente implementados en apoyo del pago a los proveedores. En este sentido, el acceso a tales mecanismos quedará sujeto a la aprobación de un plan de ajuste por parte de la Entidad Local beneficiaria con objeto de garantizar el cumplimiento del objetivo de estabilidad presupuestaria y de deuda pública. Tal y como la propia literalidad de la norma establece, el seguimiento de tales medidas: «estará sometido a rigurosas condiciones de seguimiento, remisión de información y medidas de ajuste extraordinarias» (Preámbulo).

30 Según el artículo 12.1 (regla de gasto) de la LO 2/2012, de 27 de abril: «la variación del gasto computable de la Administración Central, de las Comunidades Autónomas y de las Corporaciones Locales, no podrá superar la tasa de referencia de crecimiento del Producto Interior Bruto de medio plazo de la economía española». Además, el artículo 19 (advertencia de riesgo de incumplimiento), establece que: «1. En caso de apreciar un riesgo de incumplimiento del objetivo de estabilidad presupuestaria, del objetivo de deuda pública o de la regla de gasto de las Comunidades Autónomas o de las Corporaciones Locales, el Gobierno, a propuesta del Ministro de Hacienda y Administraciones Públicas, formulará una advertencia motivada a la Administración responsable previa audiencia a la misma. Formulada la advertencia el Gobierno dará cuenta de la misma para su conocimiento al Consejo de Política Fiscal y Financiera, si la advertida es una Comunidad Autónoma, y a la Comisión Nacional de Administración Local, si es una Corporación Local. Dicha advertencia se hará pública para general conocimiento. 2. La Administración advertida tendrá el plazo de un mes para adoptar las medidas necesarias para evitar el riesgo, que serán comunicadas al Ministerio de Hacienda y Administraciones Públicas. Si no se adoptasen las medidas o el Ministro de Hacienda y Administraciones Públicas aprecia que son insuficientes para corregir el riesgo, se aplicarán las medidas correctivas previstas en los artículos 20 y 21 y 25, apartado 1.a)». 
Finalmente, la propia regulación contenida en el Real Decreto-Ley 4/2012, de 24 de febrero, por el que se determinan obligaciones de información y procedimientos necesarios para establecer un mecanismo de financiación para el pago a los proveedores de las entidades locales, ya vino en promulgar la posibilidad de que el Gobierno del Estado retuviese las participaciones correspondientes del Ayuntamiento en los tributos del Estado ante la inobservancia de las condiciones derivadas de las obligaciones ligadas a las operaciones de crédito.

\subsubsection{El deber de información a los organismos del Estado (Ministerio de Hacienda y Administraciones Públicas)}

El artículo 4.1.c de la Ley 30/1992, de 26 de noviembre, de Régimen Jurídico de las Administraciones Públicas y del Procedimiento Administrativo Común, consagra el deber de las AAPP de «facilitar a las otras Administraciones la información que precisen sobre la actividad que desarrollen en el ejercicio de sus propias competencias» (art. 4.1.c). Adicionalmente, y al amparo de los principios de lealtad institucional, coordinación y eficacia administrativa, el artículo 55 LRBRL establece que en las relaciones recíprocas entre todas las AAPP (desde la General del Estado, hasta la autonómica y la local) se deberá «facilitar a las otras Administraciones la información sobre la propia gestión que sea relevante para el adecuado desarrollo por éstas de sus cometidos» (artículo 55.1.d), máxime cuando las mismas deberán: «valorar el impacto que sus actuaciones, en materia presupuestaria y financiera, pudieran provocar en el resto de AAPP» (artículo 55.1.c), en clara alusión a la consecución de los objetivos de déficit conjunto por parte de todas las AAPP.

En el ámbito presupuestario de las EELL, de acuerdo con el art. 193.5 (liquidación del presupuesto con remanente de tesorería negativo. Remisión a otras Administraciones públicas) del texto refundido de la Ley Reguladora de las Haciendas Locales, aprobado por el Real Decreto Legislativo 2/2004, de 5 de marzo: «las entidades locales remitirán copia de la liquidación de sus presupuestos a la Administración del Estado y a la comunidad autónoma antes de finalizar el mes de marzo del ejercicio siguiente al que corresponda. La falta de remisión de la liquidación en el plazo señalado facultará a la Administración para utilizar como actuales, a cualquier efecto, los datos que conozca relativos a la entidad de que se trate» (art. 193.5). Además, a lo largo del año 2013 se introdujeron nuevas disposiciones en esta materia a través de la Ley Orgánica 9/2013, de 20 de diciembre, de control de la deuda comercial en el sector público y de la LRSAL. Ambas leyes aprueban disposiciones en relación a la información que las EELL deberán remitir y suministrar a los organismos del Ministerio competente (Hacienda y AAPP) sobre el coste efectivo de los servicios que prestan, el período medio de pago, la información económica-financiera, o la deuda comercial, entre otras.

Las medidas y las políticas públicas consideradas a lo largo de la secuencia cronológica abordada más arriba han ido acompañadas del desarrollo de sistemas de información financiera para su remisión a las instituciones y a los organismos ministeriales, en orden al seguimiento y el cumplimiento de los objetivos de estabilidad presupues- 
taria y sostenibilidad financiera ${ }^{31}$. Así, la Ley $2 / 2011$, de 4 de marzo, de Economía Sostenible, por medio del capítulo IV (Sostenibilidad financiera del sector público) y concretamente a través del art. 33, articula las relaciones de cooperación entre las diferentes AAPP. En particular, el Ministerio de Hacienda informará a través de la Comisión Nacional de Administración Local a las EELL: «de las medidas adoptadas en cumplimiento de lo previsto en este Capítulo en el ejercicio inmediatamente anterior» (art. 33.1). Asimismo, el Gobierno articulará a partir de tales órganos y procedimientos, la adopción de las correspondientes: «medidas de racionalización y contención del gasto público en sus respectivas áreas de competencia, en especial en el marco de los planes económico financieros de reequilibrio previstos en la normativa de estabilidad presupuestaria» (art. 33.2). En caso de incumplimiento de la obligación anteriormente citada, la Secretaría General de Coordinación Autonómica y Local procederá: 1) «A retener a partir del mes de junio del ejercicio siguiente al que corresponda aquella liquidación, y hasta que se produzca la regularización de la citada remisión, así como la de las liquidaciones de los ejercicios a los que resulta de aplicación la presente norma, el importe de las entregas a cuenta y, en su caso, anticipos y liquidaciones definitivas de la participación en los tributos del Estado que les corresponda; 2. Asimismo, en el supuesto de que las Entidades Locales incumplan la obligación de remitir al Tribunal de Cuentas la información a la que se refiere el artículo 212.5 del texto refundido de la Ley Reguladora de las Haciendas Locales, aprobado por el Real Decreto Legislativo $2 / 2004$, de 5 de marzo, se podrá retener el importe de las entregas a cuenta y, en su caso, anticipos y liquidaciones definitivas de la participación en los tributos del Estado que les corresponda, y hasta que se considere cumplida tal obligación de remisión. Para que la anterior retención, o suspensión de la misma, se pueda practicar será necesaria una comunicación del Tribunal de Cuentas a la Secretaría General de Coordinación Autonómica y Local» (art. 36). Específicamente, y en base al artículo 28.k de la Ley 19/2013, de transparencia, acceso a la información pública y buen gobierno, constituye una infracción muy grave: «el incumplimiento de las obligaciones de publicación o de suministro de información previstos en la normativa presupuestaria y económico-financiera, siempre que en este caso se hubiera formulado requerimiento».

Con el propósito de armonizar los datos en materia de cumplimiento de los objetivos de estabilidad presupuestaria y sostenibilidad financiera, el Ministerio de Hacienda y AAPP recabará información sobre los Presupuestos anuales de las Corporaciones Locales, las líneas fundamentales de los mismos antes del 1 de Octubre del ejercicio presupuestario previo, así como: «la información necesaria para garantizar el cumplimiento de las previsiones de esta Ley, así como para atender cualquier otro requerimiento de información exigido por la normativa comunitaria» (art. 27, LOEPSF). Además, la necesidad de que las EELL aprueben planes de ajuste dirigidos a garantizar el

31 Esta tendencias es igualmente coherente con el reforzamiento de los mecanismos y los procedimientos desarrollados para el control de las bases de datos, no sólo las locales, sino también las autonómicas, y su interconexión con la Base de Datos Nacional de Subvenciones, superando de esa forma la previa duplicidad de las bases de datos autonómicas y locales con respecto a la base nacional de subvenciones. 
cumplimiento de los objetivos de estabilidad tras la concurrencia a un mecanismo extraordinario de apoyo a la liquidez va acompañada de la obligatoriedad de remitir a los organismos del Ministerio de Hacienda con carácter trimestral, información sobre avales, líneas de crédito, deuda comercial u operaciones con derivados (disposición adicional primera, sobre mecanismos adicionales de financiación para las Comunidades Autónomas y Corporaciones Locales, de la LOEPSF).

La Orden HAP 2105/2012, de 1 de Octubre, articula los compromisos de información previamente detallados en la LOEPSF. Bajo la responsabilidad del Ministerio de Hacienda y AAPP, autorizado para el establecimiento de los modelos y de los formatos por medio de los cuales las EELL deberán remitir la información para su publicación en la web del Ministerio, la Orden citada detalla el régimen de obligaciones para que las EELL remitan información periódica y no periódica de información presupuestaria y contable. Así, el Ministerio generará y mantendrá una base central de datos y de información pública sobre la actividad presupuestaria, económica, contable y financiera de las EELL.

En aplicación de las normas citadas, y de acuerdo con las medidas y los instrumentos de control presupuestarios implementados, coadyuvantes a los procedimientos de acceso a la información sobre las cuentas públicas locales, en el año 2013 se dispuso por vez primera de una serie trimestral de datos sobre el estado de ejecución presupuestaria de las EELL: «lo que facilita el control de las cuentas públicas en todos los niveles de la Administración» (CORA, 2013).

3.1.3. Las responsabilidades de los funcionarios locales con habilitación nacional en el control de la gestión presupuestaria y la consecución de la sostenibilidad financiera de las EELL

Conforme ha destacado el informe de la CORA, en los últimos años se ha reforzado «el papel de los Interventores municipales como funcionarios de la Administración Local con habilitación nacional» (CORA, 2013). Esta tendencia se ha producido como consecuencia de las recientes reformas sobre el régimen local que han tenido como propósito adaptar la regulación de las EELL a las disposiciones de la LOEPSF, por medio de la LRSAL, regulando fundamentalmente los diferentes mecanismos de financiación y de pago a proveedores. La Exposición de Motivos de la LRSAL establece que: «para lograr un control económico-presupuestario más riguroso, se refuerza el papel de la función interventora en las Entidades Locales», de modo que: «en la línea de garantizar la profesionalidad y la eficacia de las funciones de control interno, la Ley también regula el régimen de los funcionarios de administración local con habilitación de carácter nacional» (Exposición de Motivos LRSAL). Así, de manera concreta y a modo de ejemplo, la citada norma señala que se deberá contar con la valoración que los Interventores realizarán acerca de la sostenibilidad financiera de las diferentes propuestas planteadas acerca de la forma de gestión de los servicios públicos (art. 21). Ello se añade al preceptivo informe en caso de tener que adoptar medidas para la corrección de eventuales desequilibrios financieros, debiéndose remitir anualmente a la Intervención General de la Administración del Estado información sobre el seguimiento y los resultados de los diferentes procedimientos de control financiero. 
De acuerdo con la vigencia del Real Decreto-Ley 4/2012, de 24 de febrero, por el que se determinan obligaciones de información y procedimientos necesarios para establecer un mecanismo de financiación para el pago a proveedores de las entidades locales, los Interventores y en su caso los Secretarios-Interventores tienen encomendadas las responsabilidades de ejecutar el diseño de las medidas tendentes a liquidar las deudas contraídas con los correspondientes acreedores. De ahí que sus facultades vengan a trascender las informativas o de fiscalización. Cabe destacar que la inobservancia de las obligaciones que el citado Real Decreto-Ley 4/2012, de 24 de febrero atribuye a los Interventores, implicará la comisión de una falta muy grave.

No obstante, con carácter previo al año 2012, y a la luz de los diferentes mecanismos de financiación para el pago a proveedores, las operaciones de endeudamiento y los planes de saneamiento deberán contar con el informe favorable de la Intervención de la correspondiente Entidad Local: «que deberá pronunciarse sobre el cumplimiento de los requisitos exigidos por esta norma y la viabilidad razonada del plan de saneamiento que se somete a aprobación» (artículo 6 del Real Decreto-ley 5/2009, de 24 de abril, de medidas extraordinarias y urgentes para facilitar a las Entidades Locales el saneamiento de deudas pendientes de pago con empresas y autónomos). El nivel de responsabilidad de los funcionarios competentes a la hora de remitir las obligaciones de expedición de certificados y de comunicaciones sobre información de obligaciones pendientes de pago (tanto al Ministerio como a los contratistas), se vio ostensiblemente agravado al elevar el incumplimiento de tales obligaciones a falta muy grave, de acuerdo con lo establecido en el artículo 95 de la Ley 7/2007, de 12 de abril, del Estatuto Básico del Empleado Público.

Tal y como ha expuesto Villar Rojas y según lo expuesto, la conversión de los Interventores: «en una suerte de Interventores - Delegados del Ministerio de Hacienda, deriva de la necesidad del Informe preceptivo de los mismos en ámbitos propios de la potestad de auto-organización municipal, por tanto, propio de la oportunidad o de la política, que resulta invadida sin justificación (p. ej. Libertad de elección del modo de gestión de los servicios públicos). Lo mismo cabe decir de los informes sobre «eficiencia», que tienen carácter prospectivo y, por ende, también inciden en cuestiones de oportunidad (en línea las obligaciones información impuestas por el R.D.-Ley 4/2012)» (Villar Rojas, 2014). Si bien, conviene no obviar la importancia de la notable función desempeñada por los funcionarios locales con habilitación estatal, en el ejercicio de las labores de control de legalidad, desde la neutralidad, la independencia y la profesionalidad atribuida a dicho colectivo profesional, esencial para el correcto funcionamiento de la Administración Pública (Canales Aliende, 2010).

\section{Consideraciones finales}

Este artículo ha tenido como propósito principal analizar el impacto de las diferentes reformas que han operado sobre el régimen local español a lo largo de la secuencia cronológica comprendida entre el año 2008 y el año 2014, desde la perspectiva de las relaciones interadministrativas multinivel de contenido económico, financiero y presupuestario. Dicho estudio ha pretendido analizar la sustancial y significativa trans- 
formación que se ha venido experimentando como consecuencia de las diferentes normas aprobadas cuyo objetivo ha radicado en otorgar cumplimiento a los objetivos de estabilidad presupuestaria y sostenibilidad financiera en el marco de las EELL españolas. El trabajo se ha desarrollado por medio de una aproximación centrada en las relaciones interadministrativas establecidas entre los organismos e instituciones del Estado de una parte, y la Administración local por otro lado. Se ha evaluado el impacto y la incidencia de los sucesivos controles y mecanismos de tutela financiera sobre el margen de decisión y autonomía constitutivos de la Autonomía Local en términos económicos y financieros.

Los resultados de investigación y los análisis se han agrupado en cuatro bloques; a saber: 1) el régimen de autorización de las operaciones de crédito; 2) el control y el cumplimiento forzoso de las medidas de sostenibilidad financiera y estabilidad presupuestaria de las EELL; 3) el deber y la necesidad de información a los organismos del Estado (Ministerio de Hacienda y AAPP) por parte de las EELL; y, 4) las responsabilidades de los funcionarios de Administración Local con habilitación estatal en el control de la gestión presupuestaria y la consecución de la sostenibilidad financiera de las EELL.

Destaca la inspiración, el contenido y las consecuencias fundamentalmente economicistas de las reformas emprendidas en el ámbito local español desde el año 2008, erigidas en su mayoría y de forma predominante sobre una legitimación u orientación esencialmente basada en parámetros de eficiencia en la gestión presupuestaria. Resultan ausentes por otra parte, criterios o argumentos de naturaleza política o democrática, obviándose de esta forma el fortalecimiento de los instrumentos de participación ciudadana, la sostenibilidad de la inversión productiva o social, la garantía de la Autonomía Local, o la capacidad de las EELL para gestionar los recursos propios con mayor grado de autonomía y suficiencia financiera.

En este sentido lo reconoce la Exposición de Motivos de la LRSAL al justificar la reforma de la Administración local para adecuarla a los principios de «estabilidad presupuestaria, sostenibilidad financiera y eficiencia en el uso de los recursos públicos locales» contenidos en la LOEPSF, a la luz de la reforma del artículo 135 CE. De este modo, los propósitos de la reforma vendrán a fundamentarse sobre el propósito de «racionalizar la estructura organizativa de la Administración local de acuerdo con los principios de eficiencia, estabilidad y sostenibilidad financiera, garantizar un control financiero y presupuestario más riguroso y favorecer la iniciativa económica privada evitando intervenciones administrativas desproporcionadas» (Exposición de Motivos, LRSAL).

Según lo antedicho, el lenguaje y el discurso legitimador de las medidas para la reforma del régimen local se fundamentan en conceptos y términos tales como los de eficiencia o competitividad. La permeabilidad del régimen local resultante de la LRSAL a tales principios hace calar en el conjunto de la Administración local la vigencia de los objetivos de estabilidad presupuestaria y de sostenibilidad financiera como valores y principios estructurales y rectores de la misma. Tales motivaciones o fundamentos retóricos han venido construyendo una justificación discursiva y legal-regulatoria por medio de la cual se incluyen en las sucesivas reformas principios procedentes de la gestión ligada al sector privado o empresarial, tales como los de eficiencia, 
eficacia o economía. De esta forma, se ha consolidado la vigencia de conceptos propios de la corriente neoliberal aplicada a la Gestión Pública, tal y como prolíficamente se ha venido analizando a lo largo de los últimos años en relación al paradigma de la Nueva Gestión Pública (NGP) (Román Masedo, 2001). Dicho paradigma se ha caracterizado por la corporatización o semi-privatización de los servicios públicos, por nuevas formas de organización en el sector público, y por difuminar la frontera entre el sector público y el sector privado (Ormond y Löffler, 1999).

De este modo, las reformas no han ido acompañadas de medidas destinadas a contrarrestar los eventuales efectos provocados por la menor inversión en programas públicos. No se ha incidido en evaluar y compensar aspectos como el eventual impacto social derivado de las medidas de ajuste presupuestario, la menor capacidad de decisión para el destino de las inversiones, los mayores límites y restricciones para elaborar e implementar planes de inversión, o el mayor grado de decisión otorgado a los directivos y funcionarios encargados del control económico-financiero de las EELL. Tales consecuencias e impactos han derivado en la cada vez más restringida capacidad efectiva de decisión de las autoridades locales, fruto de las constricciones institucionales derivadas de los planes de ajuste o de saneamiento presupuestario y financiero. En la consecución e implementación de dichos planes cabe destacar la limitación del gasto público o el más relevante papel de los funcionarios locales con habilitación nacional. Todo ello limita el eventual margen de maniobra que cabría asociar a los procesos de participación ciudadana, a las estrategias de fortalecimiento democrático en la adopción de decisiones, o a la propia mejora de la representación política (democrática al fin y al cabo) en el ámbito institucional local. La imposición de estrictos controles que incrementan la tutela financiera sobre las EELL supone una limitación de la autonomía de las EELL para la adopción de ciertas decisiones de estricta idoneidad política. De esta forma, se incide negativamente en la forma por medio de la cual se articula la gestión de los recursos públicos y el destino de los mismos en función de los procesos participativos y de agregación democrática de preferencias ciudadanas.

Igualmente, los resultados evidencian la ostensible incidencia de las medidas de origen comunitario europeo acerca del control financiero de las EELL, afectando al margen y al alcance de la Autonomía Local a la luz de los controles de tutela financiera que se han institucionalizado. Se constata un cambio cualitativo como consecuencia de la mayor capacidad de control ejercida por parte de los organismos del Estado encargados de la tutela financiera. Así, se han agravado los supuestos, las condiciones y las exigencias de control financiero y del régimen de autorización requeridos para la concertación de créditos al albur de la reciente normativa europea. En este sentido, las políticas de control del gasto público han transformado de forma significativa la configuración, la articulación y la vigencia de los principios, los instrumentos y los procedimientos que han venido a imponer mayores tutelas financieras por la vía del control económico-financiero.

En consecuencia, la investigación permite evidenciar cómo las decisiones adoptadas han consolidado una tendencia de mayor dependencia jerárquica o vertical por parte de las EELL con respecto a los organismos del Estado al amparo del principio de coordinación y de tutela financiera. El escenario institucional resultante ha otorgado al Estado una mayor capacidad para ejercitar los controles sobre la actividad presupues- 
taria y las operaciones de endeudamiento de las EELL. Se ha establecido de esta forma un contexto de rigidez fruto de los requerimientos y los controles embebidos en la reciente normativa local. Así pues, la mayor disciplina presupuestaria sujeta al cumplimiento de los umbrales o límites de deuda pública y de déficit establecidos, han incidido en la Autonomía Local desde el punto de vista de la capacidad para acceder al crédito y determinar el subsiguiente destino de los fondos obtenidos. De este modo: «consideradas en conjunto, este bloque de medidas constituye un supuesto de tutela preventiva, genérica y de oportunidad, que sitúa a la Entidad Local en situación de subordinación y dependencia del Estado, que es contrario a la garantía constitucional de la autonomía local (desde STC 4/1981)» (Villar Rojas, 2014)

Los resultados exploratorios obtenidos sugieren la necesidad de ahondar en futuras investigaciones y estudios científicos que desde la óptica conceptual y metodológica de la Ciencia Política y de la Ciencia de la Administración, permitan evaluar el impacto social y democrático de las medidas adoptadas en el proceso de racionalización y de reforma del sector público local y de las propias EELL a nivel institucional y financiero. En el contexto de dicho propósito doctrinal y científico potencialmente prometedor, resultará clave avanzar en la operacionalización del principio de Autonomía Local desde el punto de vista de sus componentes y manifestaciones eminentemente democráticas y políticas, con el objeto de mensurar el impacto que sobre dichas dimensiones pueda derivarse de procesos y reformas esencialmente economicistas.

En la medida en que la legislación imprime un carácter o componente economicista a las reformas (en sus causas, procesos y resultados o consecuencias), cabe considerar una conculcación parcial del margen de decisión atribuido: 1) tanto a la Corporación Local, en tanto que depositaria de las facultades de dirección consustancialmente política; como, 2) al conjunto de la ciudadanía que constituye la comunidad local de referencia (el municipio). Cabe vislumbrar la aparición de consecuencias que afecten a dichas esferas del ámbito local, restringiendo el margen de decisión en eventuales procesos de participación ciudadana a nivel presupuestario (presupuestos participativos), e incidiendo en la necesidad de recuperar la hegemonía de la probidad y la ética pública en la gestión pública, frente a la preocupación por los costes, la eficiencia o los resultados (Olías de Lima, 2005).

Los resultados sugieren pues, la necesidad de ahondar en el estudio específico de los efectos de las sucesivas reformas analizadas sobre las diferentes dimensiones de la Autonomía Local, fundamentalmente desde la perspectiva de la dimensión democrática y eminentemente política de la misma. En cualquier caso, conviene advertir la idoneidad de que las reformas hasta ahora adoptadas desde una orientación exclusivamente economicista, vayan acompañadas de un exhaustivo y completo sumario de medidas de regeneración, modernización y fortalecimiento institucional de los procesos democráticos locales. De esta forma, se subsanaría la pendiente reforma del régimen local en términos del procedimiento participativo en lo presupuestario, la garantía de la Autonomía Local en tanto que margen de decisión o discrecionalidad de la dirección política de la Corporación Local, y la institucionalización de los cauces de participación ciudadana, de fortalecimiento asociativo y del catálogo de derechos de participación política y de acceso a la información pública a nivel local. En suma, se trataría de mejorar la eficiencia de la sociedad y el rendimiento institucional desde la 
«generación de capital social, es decir, de una ciudadanía activa y comprometida» (Olías de Lima, 2010).

\section{Bibliografía}

Almeida Cerreda, M. (2008). «¿Es necesario un nuevo modelo de controles sobre los Entes Locales?», en $R E A F$, núm. 6, pp. 187-232.

Alonso Higuera, C. (2002). Manual del Secretario. Teoría y Práctica del Derecho Muncipal. Atelier, Barcelona-

Álvarez García, V (2013). «Las reglas constitucionales sobre la interiorización del régimen local en los Estatutos de Autonomía de segunda generación y la problemática naturaleza jurídica de la Ley reguladora de las Bases de Régimen Local», en Revista Española de Derecho Constitucional, Año 33, núm. 99, sept-diciembre, pp. 61-97.

Aragonés Beltrán, E. (coord.) (2004) Ley Comentada de las Haciendas Locales. Concordancia, Jurisprudencia, consultas tributarias y doctrina. Ediciones Deusto, Barcelona.

Bachiller Rivera, M ${ }^{a}$. P. (2005). «Tutela financiera: ámbito subjetivo», en Auditoría Pública, núm. 36, pp. 101-104.

Bayo Sobrecasas, F. \& Ruíz Espinós, P. (2003). «La tutela financiera y la estabilidad presupuestaria: una reflexión sobre los diversos conceptos y sus efectos para las Haciendas Locales», en Auditoría Pública, núm. 30.

Canales Aliende, J. M. (2010). «El papel de los Secretarios de Ayuntamiento como coadyuvantes de la Administración Electoral», en Corts: Anuario de derecho parlamentario (Ejemplar dedicado a: 25 años de la aprobación de la ley orgánica de régimen electoral general: balance y perspectivas), núm. 24, págs. 27-41. Corts Valencianes, Valencia.

Canales Aliende, J.M. \& Pérez, P. L. (2002). Introducción al Gobierno y a la Gestión local. Editorial Club Universitario (ECU), Alicante

Carbonero, J. M. (coord.) (2008). Administración Local Práctica. La Ley (Grupo Walters Kluwer), Madrid.

Casado Caballero, G. (2008). «La financiación de las organizaciones locales: principios de autonomía y suficiencia financiera», en Quintana, J. P. (director), Globalización y principio de autonomía local. Consejo General del Poder Judicial (CGPJ), Madrid.

Chandler, R. \& Plano, J. (1988). The Public Administration Dictionary. Thousand Oacks, California.

Cliset Borrell, F. \& Grau Ávila, S. (1992). «La Función Pública Local», Informe sobre el Gobierno Local. INAP, Madrid.

Colino, C. (2011). «Federalismo horizontal en el Estado Autonómico. La evolución de los mecanismos de cooperación horizontal en España», en Cuadernos Manuel Giménez Abad, 2, pp. 1-13.

Collado Yurrita, M. A. (dir.) \& Luchena Mozo, G. Ma . (coord.) (2011). Derecho Financiero y Tributario. Atelier (libros jurídicos), Barcelona.

Consejo de Europa (1985). Carta Europea de la Autonomía Local. Consejo de Europa, Estrasburgo.

Crespo, J. (2002). «Relaciones entre Administraciones Públicas en España», en Crespo, J. y Pastor, G. Administraciones Públicas Españolas. Mc Graw Hill, Madrid.

De Vicente García, J. (2002). La autonomía local: un estudio a través de la Constitución, la Jurisprudencia y el Derecho Comparado. UIM, Granada. 
Endemaño Arostegi, J. M M $^{\mathrm{a}}$ (2014). «Alcance y ubicación del título competencial tutela financiera sobre los municipios», Zergak, n 46, pp. 165-186.

Esteve Pardo, J. (1991). Organización supramunicipal y sistema de articulación entre Administración Autonómica y orden local. La experiencia de la RFA. Bases y perspectivas en España. Civitas, Marid.

Ezquiaga Domínguez, I. \& Muñoz Muñoz, F. A. (1996). «Gestión financeira y endeudamiento de las corporaciones locales», en Papeles de economía española. pp. 252-275.

García-Escudero Márquez, P. (2013). «Sobre la reforma del artículo 135 de la Constitución», en Crónica Parlamentaria 1/2013, Instituto Estudios Fiscales, pp. 94-105.

González Temprano, A. (2014). «Crisis económica y Sector Público en los países desarrollados», en Cuadernos de Gobierno y Administración Pública, $\mathrm{n}^{\circ}$ 1, vol. 1, pp. 57-75.

Huelín Martínez de Velasco, J. (2008). «El papel de las Entidades Locales en el proceso de construcción europea», en Quintana, J. P. (director), Globalización y principio de autonomía local. Consejo General del Poder Judicial (CGPJ), Marid.

Martínez Lago, M. Á. (2011). «El régimen jurídico del endeudamiento de las Entidades Locales y las restricciones para su ejercicio en 2011», en Anuario Aragonés de Gobierno Local, $\mathrm{n}^{\mathrm{o}} 2$, pp. 213-242.

Menéndez Moreno, A. (2008). Derecho Financiero y Tributario Español. Normas Básicas. Lex Nova, Valladolid.

Ministerio de Administraciones Públicas. (2005). Libro Blanco para la Reforma del Gobierno Local. Ministerio de Administraciones Públicas, Secretaría General Técnica, Madrid.

Navarro Fauré, A. (2012). «Haciendas locales», en Díez Sánchez, J. J. \& Ivars Bañuls, J. A. (coord.), Comentarios a la Ley de régimen local de la Comunitat Valenciana: Ley 8-2010 de la Generalitat. Tirant lo Blanch, Valencia.

Navarro Fauré, A. (2013). «El Estado social y los principios del gasto público y de la deuda pública en una Hacienda globalizada», en López Garrido, D. (dir.). Reforma constitucional y estabilidad presupuestaria. Centro de Estudios Políticos y Constitucionales (CEPC), Madrid.

Olías de Lima, B. (2010). «Estrategias para el buen gobierno y la buena gestión local (eficiencia, modernización, participación y calidad democrática)», en El municipalismo en un Estado cooperativo. FEMP, Madrid.

Olías de Lima, B. 2002. «Las Administraciones Públicas españolas: balance y perspectivas», en G. Pastor y J. Crespo (coord.), Administraciones Públicas Las Españolas. Balance y perspectivas. Graw Hil, Madrid.

Olías de Lima, B. 2005. «Servicios públicos y gobernanza», en Revista Sistema, n 184-185, pp. 125-140.

Pérez López, G., Plata Díaz, A. Maa., Zafra Gómez, J. L. \& López Hernández, A. M. (2013). «Deuda viva municipal en un contexto de crisis económica: análisis de los factores determinantes y de las formas de gestión», en Revista de Contabilidad, n 2 , vol. 16, pp. 83-93.

Pérez Royo, F. (2010). Curso de Derecho Tributario. Tecnos, Madrid.

Queralt et alt. (2011). Curso de Derecho Financiero y Tributario. Tecnos, Madrid.

Quintana, J. P. (director) (2008). Globalización y principio de autonomía local. Consejo General del Poder Judicial (CGPJ), Madrid.

Ramos Prieto, J. (2003). «Autonomía, suficiencia financiera y poder tributario de las Corporaciones Locales ante el creciente avance del poder tributario de las Comunidades Autónomas», en Revista de Estudios Regionales, nº 66, pp. 167-184.

Ruano, J. M. (2002). «Las Administraciones locales», en Crespo, J. y Pastor, G. Administraciones Públicas Españolas. Mc Graw Hill, Madrid. 
Sánchez Sáez, A. (2008). Autonomía Local y Descentralización. Su naturaleza jurídica. Tirant Monografías, Valencia.

Tejerizo López, J. M. (2003). «Relaciones entre los diferentes niveles del sistema tributario español a la luz de la reforma de las HHLL», en Jornadas sobre la reforma de la Ley de HHLL, Santa Cruz de Tenerife.

Tocqueville, A. (1980). La Democracia en América. Madrid: Alianza.

Vallès, J. M. \& Brugué, Q. (2001). «El Gobierno Local», en Alcántara, M. \& Martínez, A. (eds.), Política y Gobierno en España. Tirant lo Blanch, Valencia.

Villar Rojas, F. J. (2014). «Razones y contradicciones de la Ley de Racionalización y Sostenibilidad de la Administración Local», Estudios y comentarios. INAP («La Administración al Día»), Madrid. 